\title{
Inventário e avaliação quantitativa de geossítios: exemplo de aplicação ao patri- mônio geológico do município de Caçapava do Sul (RS, Brasil)
}

\author{
André Weissheimer de BORBA ${ }^{1}$, Luiz Fernando de SOUZA², Ana Maria Pimentel MIZUSAKI ${ }^{3}$, Delia del \\ Pilar Montecinos de ALMEIDA ${ }^{4}$ \& Paola Prates STUMPF 5
}

1. Universidade Federal de Santa Maria, Centro de Ciências Naturais e Exatas, Departamento de Geociências. Av. Roraima, 1000, prédio 17, sala 1131B, Camobi, 97105-900, Santa Maria, RS, Brasil. E-mail: awborba.geo@gmail.com.

2. Ministério Público do Estado do Rio Grande do Sul, Divisão de Assessoramento Técnico, Unidade de Assessoramento Ambiental. Rua Andrade Neves, 106, 10 andar, Centro, 90010-210, Porto Alegre, RS, Brasil. E-mail: luizfsouza@mp.rs.gov.br.

3. Universidade Federal do Rio Grande do Sul, Instituto de Geociências. Avenida Bento Gonçalves, 9500, prédio 43127, Agronomia, 91501970, Porto Alegre, RS, Brasil. E-mail: ana.mizusaki@ufrgs.br.

4. Universidade Federal do Pampa, Unipampa, Campus Caçapava do Sul. Av. Pedro Anunciação, s/n, Vila Batista, 96570-000, Caçapava do Sul, RS, Brasil. E-mail: delia.almeida@unipampa.edu.br.

5. Secretaria Estadual do Meio Ambiente, Divisão de Unidades de Conservação. Av. Borges de Medeiros, 261, Centro, 90020-021, Porto Alegre, RS, Brasil. E-mail: paola-stumpf@sema.rs.gov.br.

Recebido em 02/2013. Aceito para publicação em 11/2013.

Versão online publicada em 13/12/2013 (www.pesquisasemgeociencias.ufrgs.br)

\begin{abstract}
Resumo - Este trabalho apresenta um inventário, com valoração quantitativa, de 46 geossítios componentes do patrimônio geológico do Município de Caçapava do Sul, região importante na pesquisa geocientífica no Estado do Rio Grande do Sul. Os lugares selecionados para avaliação, contemplando grandes áreas, afloramentos simples e potenciais miradores em rodovias, representam os quatro grandes contextos geológicos inseridos no território municipal. 0 sistema de valoração aplicado considera critérios geocientíficos, ecológicos, culturais, estéticos, econômicos e de uso potencial, resultando em índices (na escala de 1 a 10$)$ de valor educativo $\left(V_{\text {educ }}\right)$, turístico $\left(\mathrm{V}_{\text {tur }}\right)$ e de necessidade de proteção $\left(\mathrm{V}_{\text {prot }}\right)$ para cada um dos geossítios. Os destaques do estudo são as Pedras das Guaritas, a Pedra do Segredo e a Pedra do Leão, entre diversos outros geossítios com grande potencial para educação, turismo e esportes de aventura na natureza. Lugares de conflito entre sua importância geopatrimonial e sua exploração econômica, como a área das Caieiras e as Minas do Camaquã, resultam nos maiores valores de necessidade de proteção. Os resultados permitiram a definição e sugestão de prioridades de atuação para instituições públicas, privadas e do terceiro setor em suas iniciativas de geoconservação. Tais iniciativas devem integrar projetos educacionais e turísticos, implantação da infraestrutura necessária, e ainda estabelecimento de unidades de conservação da natureza (UC) naquela região de patrimônio natural singular e de grande potencial para o desenvolvimento sustentável.
\end{abstract}

Palavras-chave: geoconservação, patrimônio geológico, geossítios, avaliação quantitativa, Caçapava do Sul.

\begin{abstract}
InVENTORY AND QUANTITATIVE ASSESSMENT OF GEOSITES: APPLICATION TO THE GEOLOGICAL HERITAGE of THE Municipality of CAÇAPAVA do Sul (RS, BRAziL). This paper presents an inventory and quantitative assessment of 46 geosites, which compose the geological heritage of the municipality of Caçapava do Sul, important center of geoscience research in the Rio Grande do Sul State. The selected sites comprise large areas, single outcrops and potential highway viewpoints that represent the four main geological contexts of the considered territory. The applied quantitative assessment system considers six sets of criteria: geoscience, ecology, culture, esthetics, economy and potential use. Its application results in educational $\left(\mathrm{V}_{\text {educ }}\right)$, tourist $\left(\mathrm{V}_{\text {tur }}\right)$ and protection need $\left(\mathrm{V}_{\text {prot }}\right)$ indexes in the scale from 1 to 10 , for each of the geosites. The study highlighted the sites Pedras das Guaritas, Pedra do Segredo, and Pedra do Leão as having great potential for education and tourism, as well as for outdoor sports. Sites with conflict between geoheritage significance and economic exploration, as the Caieiras and Minas do Camaquã mining districts, resulted in the most expressive protection need indexes. The obtained results allowed the definition and suggestion of priorities for public, private, and third-sector institutions concerning possible geoconservation initiatives. Such initiatives shall integrate education, tourism, infrastructure development, and the establishment of protected areas for this region of singular natural heritage with a huge potential for sustainable development.
\end{abstract}

Keywords: geoconservation, geological heritage, geosites, quantitative assessment, Caçapava do Sul. 


\section{Introdução}

O termo geoconservação designa o conjunto de metodologias, estratégias e práticas destinadas a avaliar, proteger, valorizar e divulgar os geossítios que compõem o patrimônio geológico de uma determinada região (Sharples, 2002; Brilha, 2005; Gray, 2008; Pena dos Reis \& Henriques, 2009; Henriques et al., 2011; revisão de conceitos em Borba, 2011). Para Henriques et al. (2011), os procedimentos de inventário e avaliação quali-quantitativa de geossítios constituem a "geoconservação básica", ou seja, os procedimentos mais fundamentais e que irão embasar subsequentes estratégias de proteção e valorização dos lugares de interesse geológico. Efetivamente, inventários e avaliações quantitativas são importantes para uma aplicação direcionada e eficaz, do ponto de vista socioambiental, do conhecimento geológico existente sobre uma região ou sobre um contexto em particular. Tais avaliações são decisivas no momento de levar a gestores públicos e à comunidade propostas de "aplicações técnicas da geoconservação" (Henriques et al., 2011): criação de unidades de conservação, elaboração de projetos (geo) educativos, implementação de roteiros geoturísticos, entre outros.

O município de Caçapava do Sul, com uma área total de $3.047 \mathrm{~km}^{2}$ e uma população em torno de 33.000 habitantes, situa-se na região centro-sul do Rio Grande do Sul, a $260 \mathrm{~km}$ de Porto Alegre. 0 município está posicionado na porção central do Escudo Sul-rio-grandense (Chemale Jr., 2000) e na região geomorfológica do Planalto Sul-rio-grandense (Justus et al., 1986), área de expressiva geodiversidade, resultado de uma evolução geológica longa e complexa (do Paleoproterozoico ao Recente), e dotada de paisagens de substancial atratividade turística. A geologia de Caçapava do Sul tem sido focalizada em inúmeros trabalhos científicos de grupos de pesquisa nacionais e internacionais, desde os trabalhos pioneiros (Carvalho, 1932; Leinz et al., 1941) até os dias atuais. Além de ter servido, desde sempre, como "acampamento-base" para as expedições científicas e saídas a campo de grupos de estudantes das ciências naturais, hoje a cidade conta com um campus universitário (Universidade Federal do Pampa - Unipampa) dedicado às geociências, com cursos de geofísica, geologia e tecnologia em mineração, entre outros (www.unipampa.edu.br). Entretanto, a região apresenta problemas sérios do ponto de vista humano e socioambiental: (a) baixos índices de escolaridade entre os adultos; (b) altas taxas de evasão escolar entre as crianças; (c) notas baixas no ENEM (Exame Nacional do Ensino Médio), especialmente em ciências da natureza; (d) absoluta inexistência de unidades de conservação da natureza (UC) de iniciativa estatal no município, que atualmente experimenta uma retomada dos investimentos em mineração de metais e uma proliferação de empreendimentos de silvicultura de espécies florestais exóticas.
O presente trabalho contempla os passos iniciais de uma estratégia de geoconservação para o município, através da realização de um inventário de geossítios e de uma avaliação quantitativa dos mesmos pela aplicação, com pequenas modificações, de metodologia desenvolvida por Fassoulas et al. (2012). Optou-se por contemplar os limites político-administrativos do município em virtude do viés social da geoconservação, que demanda políticas e instrumentos de gestão de âmbito local. Os resultados apresentados poderão, no futuro, ser utilizados para a definição de prioridades e estratégias para a gestão e utilização sustentável da geodiversidade e do patrimônio geológico de Caçapava do Sul. Espera-se que as informações aqui divulgadas possam ser incluídas em práticas de gestão territorial não apenas pela municipalidade, mas também por outros organismos governamentais (estaduais e/ou federais) e não-governamentais (iniciativa privada e terceiro setor) das áreas de educação, turismo, planejamento e proteção ambiental.

\section{Panorama natural e evolução geológica}

O município de Caçapava do Sul (limites na Fig. 1) insere-se, em termos geológicos, no Escudo Sul-rio-grandense (ESRG), área que registra processos magmáticos, metamórficos, sedimentares e metalogênicos variados, com idades desde o Paleoproterozóico $(2,48$ Ga, Hartmann et al., 2000) até o Paleozóico inferior (Paim et al., 2000; Borba, 2006; Borba et al., 2008; Maraschin et al., 2010). A "sutura de Caçapava" (Costa et al., 1995), estrutura tectônica de escala crustal que secciona o território do município na direção NE-SW, separa terrenos Paleoproterozoicos, com cobertura supracrustal mais jovem, a leste (domínio Santana da Boa Vista, unidades Encantadas e Porongos), de associações ígneas e metamórficas juvenis do Neoproterozoico (domínio São Gabriel, unidades Cambaí e Vacacaí), a oeste (Chemale Jr., 2000). Esses registros de embasamento são recobertos por unidades sedimentares e vulcanogênicas espessas, depositadas na transição do Neoproterozoico ao Paleozóico inferior e vinculadas aos domínios da "Bacia do Camaquã" (Paim et al., 2000; Borba, 2006).

Considerando a subdivisão geomorfológica do Rio Grande do Sul, a área se insere na região geomorfológica do Planalto Sul-rio-grandense, contendo as unidades de relevo 'Planaltos Rebaixados Canguçu-Caçapava' e 'Planaltos Marginais Rebaixados', caracterizadas sobretudo por relevo dissecado em colinas, áreas de topo plano, interflúvios tabulares, encostas íngremes, cornijas e cristas (Justus et al., 1986). Naquela região se encontram as maiores altitudes da "metade sul" do Estado, próximas a 500 m.s.n.m. (CPRM, 2009). Serras e morros alongados, com solos rasos e afloramentos de granitos e riolitos, dominam a porção norte do município, enquanto a porção sul é caracterizada pela presença dos cerros ruiniformes designados pelo ter- 
mo regional "guaritas" (CPRM, 2009). Em Caçapava do Sul está o divisor de águas entre duas importantes bacias hidrográficas rio-grandenses: a bacia do rio Jacuí, a norte, que recebe as águas e sedimentos dos arroios Santa Bárbara e Irapuá; e a bacia do rio Camaquã, a sul, que recebe o aporte dos arroios Lageado, Passo da Areia e João Dias, entre outros. Mosaicos campo-floresta e vegetação ripária ao longo dos cursos d'água caracterizam os principais ecossistemas da região, que apresenta diversas espécies endêmicas e ameaçadas de extinção (Guadagnin et al., 2000; Borba \& Souza, 2010).

A complexa e longa evolução geológica dos terrenos inseridos dentro dos limites do município de Caçapava do Sul (Fig. 1) pode ser sintetizada nas seguintes fases: (1) a existência de um embasamento antigo, Paleoproterozoico (Hartmann et al., 2000), com sedimentação química, marinha, de carbonatos da mesma faixa de idade (Neis et al., 2012); (2) o desenvolvimento de bacias vulcanossedimentares proterozoicas, de idade indefinida, com posterior metamorfismo em graus variados, registradas pelas rochas do complexo Passo Feio (Bitencourt, 1983; Hartmann et al., 2000); (3) o desenvolvimento de bacias vulcanossedimentares neoproterozoicas, com sedimentação marinha e alúvio-lacustre, registradas nas unidades Maricá, Bom Jardim e Acampamento Velho, com idades entre 630 e $549 \mathrm{Ma}$ (Almeida et al., 2005; Borba et al., 2007; Borba et al., 2008; Almeida et al., 2012; Janikian et al., 2012); (4) o posicionamento e cristalização do complexo granítico de Caçapava do Sul, ao longo de zona de cisalhamento, em torno de 550 Ma (Sartori \& Kawashita, 1985; Leite et al., 1995); (5) a sedimentação dos sistemas aluviais, fluviais, lacustres e eólicos, em ambiente semi-desértico, com vulcanismo basáltico subordinado, das unidades Santa Bárbara, Guaritas e Rodeio Velho, já no Paleozoico inferior (Paim et al., 2000; Borba \& Mizusaki, 2003; Almeida et al., 2005; Borba, 2006; Hartmann et al., 2008; Maraschin et al., 2010; Almeida et al., 2012); (6) os soerguimentos diferenciais dos blocos tectônicos da região, com reativação de estruturas preexistentes, durante o Paleozoico e Mesozoico, comportando-se como embasamento da Bacia do Paraná (Borba et al., 2002; Borba et al., 2003; Silva et al., 2006); e (7) sua evolução geomorfológica durante as flutuações climáticas do Quaternário, incluindo condições mais áridas que as atuais (Suertegaray \& Silva, 2009), com o desenvolvimento, entre outras formas de relevo, das feições ruiniformes características das áreas das Pedras das Guaritas (Paim et al., 2010) e Serra do Segredo (Borba et al., 2011). Essa diversidade de processos e terrenos resulta em uma gama de ambientes com diferentes características de relevo, solo, umidade, substrato e exposição solar, entre outros, culminando na formação de múltiplos habitats para as espécies da fauna e flora nativas da região.

\section{Metodologia}

\subsection{Seleção dos geossítios}

O inventário do patrimônio geológico de Caçapava do Sul foi elaborado, inicialmente, com base na experiência do grupo de pesquisa e na consulta à bibliografia especializada. Foram considerados como potenciais geossítios todos os afloramentos naturais, acidentes geográficos principais, cortes de estrada em rodovias asfaltadas, pedreiras e minas ativas e/ou abandonadas, além de pontos estratégicos em rodovias para atuarem como miradores. Dentre esses, selecionaram-se, para efeitos deste inventário, locais: (a) descritos, representados ou citados em publicações científicas relevantes ou mapas geológicos da região (e.g. CPRM, 1995; UFRGS, 1998; CPRM, 2009); (b) utilizados usualmente para aulas práticas (saídas a campo) em qualquer subárea das ciências da Terra, que exemplifiquem feições significativas (interesse didático); (c) onde tenham sido identificadas, definidas, obtidas ou nomeadas unidades estratigráficas, ocorrências minerais, idades absolutas e outras informações geológicas relevantes, ou onde estas ainda possam ser obtidas pela qualidade da exposição (interesse científico); (d) que sejam visitados regularmente por público externo à comunidade local ou que possuam potencial de atração de turistas (interesse turístico); e/ou (e) que sejam utilizados regularmente pelas comunidades locais como áreas de lazer ou balneários e que possuam elementos evidentes e significativos de geodiversidade (interesse recreativo).

Adicionalmente, a partir de modelo digital de elevação (MDE) do estado do Rio Grande do Sul, obtido a partir dos dados SRTM (Shuttle Radar Topography Mission) e disponibilizado pelo Laboratório de Geoprocessamento do Centro de Ecologia da Universidade Federal do Rio Grande do Sul (Weber et al., 2004), foram selecionados locais com declividades acentuadas, acima de $40^{\circ}$, para verificação no campo e avaliação sobre sua efetiva caracterização como potencial geossítio. A partir dos procedimentos descritos acima foram identificados, apenas dentro dos limites municipais de Caçapava do Sul, 46 geossítios (Tabs. 1-3, e fig. 1). Cada um dos geossítios, visitado em campo, teve suas principais características e feições descritas e fotografadas, além de registrados seu contexto geológico e a unidade estratigráfica correspondente. A partir das coordenadas obtidas em aparelho GPS, os pontos de referência de cada geossítio foram plotados em SIG através do programa SPRING (Camara et al., 1996). No campo e com o apoio do software de visualização de imagens de satélite GoogleEarth ${ }^{\mathrm{T}}$, foram obtidas as distâncias dos geossítios em relação à zona urbana de Caçapava do Sul, por rodovias asfaltadas, estradas vicinais de "chão batido" e percursos pedestres eventualmente necessários para acessá-los. 


\subsection{Atribuição de notas nos diferentes critérios}

Os geossítios foram classificados e valorados através da aplicação, com pequenas modificações, da metodologia elaborada por Fassoulas et al. (2012), que se alicerça na atribuição de notas de 1 a 10 para seis blocos de critérios, a saber: critérios (a) científicos, (b) ecológicos, (c) culturais, (d) estéticos, (e) econômicos e (f) de uso potencial. Após a aplicação de toda a tabela de avaliação, a cada geossítio corresponderá uma nota final, composta e ponderada, também na escala de 1 a 10. Notas nessa escala são adequadas para uma divulgação dos resultados à sociedade e, sobretudo, para eventuais esforços no sentido de convencer gestores municipais a priorizar determinados geossítios para intervenções ou proteção. Outros sistemas de valoração (e.g. Bruschi, 2007; Lima et al., 2010) parecem mais aplicáveis a grandes territórios, como o brasileiro, e não ao patrimônio geológico na escala municipal, onde realmente vivem as comunidades, e onde se encontram os problemas e as ferramentas institucionais disponíveis para seu enfrentamento.

O bloco de critérios científicos merece destaque por refletir mais diretamente as características geológicas dos lugares selecionados. Para o critério "história geológica", por exemplo, a avaliação tomou como referência as sete fases da evolução da região de Caçapava do Sul, descritas sucintamente ao final do item anterior. Um geossítio ideal, hipotético, em que fosse possível a visualização ou demonstração de todas as sete fases com perfeição, mereceria a nota 10 . Um geossítio excelente (neste critério) como a Pedra do Segredo permite a demonstração segura aos visitantes, pelo menos, das fases 7, 6 e 5 da evolução geológica descrita no item anterior (formação das formas de relevo no Quaternário, soerguimentos diferenciais e sedimentação continental no Paleozoico inferior). Além disso, por sua proximidade com outras unidades, quem se posiciona no topo da Pedra do Segredo pode ainda visualizar e receber informações, mesmo que à distância, sobre locais representativos das fases 4,3 e 2 da referida história geológica (colocação dos granitos de Caçapava, bacias vulcanossedimentares metamorfizadas ou não metamorfizadas). Optou-se por atribuir a nota 10 para cada fase demonstrada in loco e a nota 4 para cada fase passível de interpretação à distância, somando-se todas e dividindo por sete, o número total de fases. Dessa forma, a Pedra do Segredo recebeu 42 pontos $(10+10+10+4+4+4)$ que, divididos por 7 , forneceram sua nota final no critério "história geológica", 6 (Tab. 1).

0 critério "geodiversidade" também foi avaliado de uma forma singular, com base em sua própria conceituação, introduzida por Gray (2004): "a variedade natural de feições ou elementos geológicos" presentes em um território ou, neste caso, em um geossítio. Considerando que o presente trabalho traz uma abordagem de geoconservação, voltada à integração do conhecimento geológico com a sociedade, foram con- sideradas apenas aquelas feições passíveis de compreensão por um público de estudantes ou turistas, mediante uma explanação, em linguagem acessível, por um especialista treinado ou por um bom painel (ou folheto) interpretativo. Assim, foi realizada, para cada geossítio, uma contagem simples de feições ou elementos geológicos. Utilizando novamente a Pedra do Segredo como exemplo, naquele geossítio são passíveis de visualização e compreensão as seguintes feições: (a) como tipos de rocha, os conglomerados, os arenitos conglomeráticos e os clastos (seixos, blocos) de outras rochas, sem detalhamento de proveniência (3 elementos); (b) como estruturas componentes da fácies, a geometria lenticular e as estratificações cruzadas acanaladas (2 elementos); (c) como feições geomorfológicas, a forma de relevo ruiniforme em si, as janelas de abrasão eólica, a gruta, a alteração alveolar (tafoni) nas paredes da gruta e a estalactite calcária (5 elementos); e (d) como feições tectônicas, o leve basculamento das camadas e as falhas/fraturas presentes no local (2 elementos); a contagem total desses elementos, todos passíveis de explicações em linguagem acessível, fornece o número 12. Todos os geossítios foram avaliados dessa maneira e, considerando que 12 foi o máximo valor encontrado, este número foi transformado na nota máxima (10) e os resultados para os outros locais foram calculados proporcionalmente.

Os demais critérios do bloco científico foram avaliados de forma subjetiva e comparativa: para "representatividade", notas de 1 a 10, reservando-se as notas mais altas para geossítios altamente representativos do patrimônio geológico da área ou do contexto considerado, incluindo as seções-tipo; para "raridade", valores desde 1 para locais comuns, similares a outros na mesma região, até 10 para geossítios únicos, sem paralelo no contexto e no território considerados; e para "integridade", desde 1, para geossítios quase totalmente destruídos, até 10, no caso de locais com feições geológicas preservadas em sua totalidade. Os critérios ecológicos salientam a importância de uma equipe de trabalho multidisciplinar, com a presença de pesquisadores ou profissionais da área de biota: o critério "estruturação de habitats" (originalmente "ecological impact") relaciona-se com a contribuição da estrutura física do geossítio para o desenvolvimento ou manutenção de ecossistemas peculiares, ou para a presença de espécies raras, endêmicas ou ameaçadas; e o critério "status de proteção", que reflete o quanto o ecossistema está protegido (pela legislação) e preservado (na prática).

O bloco de parâmetros culturais foi modificado em relação àquele de Fassoulas et al. (2012), tendo-se excluído os critérios que relacionam os geossítios ao desenvolvimento da "ética" e da "religião" de uma sociedade. Tais parâmetros são muito significativos para uma pesquisa na Grécia, mas pouco expressivos para uma região onde a ética e a religião de seus habitantes originais (guenoas, charruas, guaranis e seus antepassados) foi obliterada por conceitos e dogmas trazidos 
por colonizadores europeus. É possível que as áreas rochosas das Serras do Sudeste e do Escudo Sul-rio-grandense tenham influenciado a ética, os costumes e as crenças religiosas dos povos autóctones desta região da América do Sul, mas tais registros não chegaram às gerações atuais. Assim, o bloco de critérios culturais permaneceu apenas com os critérios "história" (vinculação do geossítio a eventos históricos) e "arte \& cultura" (utilização do geossítio em todos os tipos de arte, manifestações culturais e/ou como símbolo da região). Os critérios estéticos, "visibilidade" e "destaque na paisagem", referem-se respectivamente: à capacidade de um geossítio de ser observado de diferentes pontos de observação distantes mais de um quilômetro entre si (nota 1 para locais sem visibilidade, como afloramentos em corte de estrada ou lajeados em arroios, e 10 para cerros visíveis de diversos pontos e a grandes distâncias, como o Cerro da Angélica, por exemplo); e às diferenças em forma, textura e cor entre o geossítio e o seu entorno, que fazem com que aquele local se destaque na paisagem.

Para os blocos de critérios econômicos e de uso potencial, cabe uma ressalva, uma vez que os parâmetros "proteção oficial", "intensidade de uso" e "degradação" recebem uma avaliação com lógica invertida em relação aos demais. Nesses, atribui-se a nota máxima (10) para geossítios não protegidos por unidades de conservação da natureza (no caso de Caçapava do Sul, todos), não utilizados para qualquer fim e que não tenham impactos potenciais ou processos de degradação efetivos a ameaçar sua integridade ou visibilidade. Nos critérios "visitantes" e "nível da atração", receberam as maiores notas os geossítios relacionados à Serra do Segredo (Pedra do Segredo, Pedra do Leão), além das Pedras das Guaritas, os quais já possuem visitação turística, ainda que reduzida, e prática de esportes de aventura. Especificamente para a estimativa de "visitantes", também mereceram notas relativamente destacadas aqueles geossítios posicionados no interior de empreendimentos turísticos (como os campos de matacões na pousada Chácara do Forte) e recreativos (no caso da Pedra da Guarda Velha, geossítio posicionado dentro de piquete/balneário), bem como aqueles geossítios na área urbana e na rodovia BR-290. É importante salientar, contudo, que não há controle do número ou do perfil de eventuais visitantes a qualquer dos locais avaliados, o que seria essencial para futuras estratégias de divulgação do patrimônio geológico da região.

Para o critério "fragilidade", receberam notas mais altas (ou seja, foram considerados mais frágeis) geossítios pontuais (afloramentos simples) dotados de feições geológicas delicadas, como as pillow-lavas arroio Mudador (Chaves et al., 2011) ou as lavas em corda, lavas em tubo e peperitos do arroio Carajá (Petry \& Almeida, 2005), por exemplo, ou afloramentos frágeis dentro de áreas complexas, como as feições tafoni na gruta situada no interior da Pedra do Segredo. Uma atenção maior para esses tipos de geossítios, es- pecificamente em termos de fragilidade e intervenção mais urgente, já havia sido recomendada por Fuertes-Gutiérrez \& Fernández-Martínez (2010). Para o critério "acessibilidade", foram considerados como os mais acessíveis (notas mais altas), a partir da zona urbana de Caçapava do Sul (onde estão escolas, hotéis e universidades) aqueles geossítios posicionados em rodovias asfaltadas, mesmo que o trecho em asfalto seja longo. Isso se justifica no sentido de que a abordagem de geoconservação deve considerar a possibilidade de visitação por grupos maiores (em vans ou ônibus), grupos de idosos ou pessoas com necessidades especiais, ou grupos de crianças, para os quais trajetos em estradas vicinais, de "chão batido" e, sobretudo, percursos pedestres, podem representar severas limitações. As "mudanças aceitáveis" são maiores para os potenciais miradores, uma vez que seu aproveitamento envolve adequações em termos de infraestrutura, e menores para os geossítios mais frágeis (Tab. 2).

Por fim, é importante salientar que os geossítios indicados como potenciais miradores, localizados em rodovias asfaltadas, foram avaliados de forma um pouco diferenciada. Para todos os critérios do bloco científico, assim como para os critérios "diferenciação na paisagem" e "nível da atração", a atribuição da nota considerou a paisagem e as feições visualizadas a partir do mirador, e não as características do ponto em si. Por outro lado, para todos os demais critérios, incluindo "acessibilidade", "fragilidade" ou "impactos", as notas se referem ao local em si, o qual poderá constituir um mirador. Essa diferenciação na avaliação reflete um pouco da complexidade de se avaliarem diversos geossítios com características diferentes, e que pode levar a algumas distorções nos resultados.

\subsection{Cálculo dos índices de valor}

A média das notas referentes aos diversos critérios, dentro dos respectivos blocos, resulta nos escores científico, ecológico, cultural, estético, econômico e de uso potencial (Tabs. 1-2). Dentro do bloco ecológico, além do escore em si, calcula-se ainda o fator de risco ecológico $\left(F_{\text {ecol }}\right)$, dividindo-se a nota do critério "estruturação de habitats" por aquela do critério "status de proteção". A partir dos escores resultantes e do fator ecológico, calculam-se os índices de valor educativo $\left(V_{\text {educ }}\right)$, valor turístico $\left(V_{\text {tur }}\right)$ e valor de necessidade de proteção $\left(V_{\text {prot }}\right)$, através das seguintes operações:

$$
\begin{aligned}
& V_{\text {educ }}=0,4 \text { (escore científico) }+0,2 \text { (escore cultural) }+0,2 \\
& \text { (escore estético) }+0,2 \text { (escore ecológico) }
\end{aligned}
$$

$V_{\text {tur }}=0,4$ (escore estético) $+0,2$ (escore cultural) $+0,2$ (escore de uso potencial) + 0,2 (escore econômico)

$V_{\text {prot }}=\left\{\right.$ escore científico $+F_{\text {ecol }}+(11-$ critério "integrida$\left.\left.d e^{\prime \prime}\right)\right\} / 3$. 
Dessa forma, o sistema de valoração proposto por Fassoulas et al. (2012) e aplicado no âmbito deste trabalho considera que o valor educativo $\left(V_{\text {educ }}\right)$ de um geossítio é fortemente dependente: (a) de suas potencialidades científicas, em termos de geodiversidade, representatividade e outros parâmetros; (b) de seu impacto cultural e ecológico, ou seja, o quanto aquele local é importante para os ecossistemas e para a população local; e (c) de seu apelo estético, em termos de beleza cênica e imponência na paisagem. Por sua vez, o valor turístico $\left(V_{t u r}\right)$ depende preponderantemente da visibilidade e diferenciação na paisagem, mas também de aspectos culturais, econômicos, como número de visitantes, e de uso potencial, como a acessibilidade e a capacidade de aceitar mudanças, que por vezes são necessárias ao aproveitamento turístico de uma área ou, por exemplo, de um mirador. Por fim, o valor de necessidade de proteção $\left(V_{\text {prot }}\right)$ é vinculado ao potencial científico, ao risco ecológico envolvido e ao grau de integridade dos locais de interesse geológico: quanto mais danificado um afloramento ou uma área, e quanto mais ameaçado seu ecossistema associado, maior será a necessidade de adoção de medidas protetivas.

\section{Resultados e discussão}

\subsection{Escores e índices de valor obtidos}

Os geossítios avaliados (numerados de 1 a 46 na figura 1), suas coordenadas geográficas, as notas atribuídas para cada critério pela equipe de trabalho, os escores médios resultantes para cada bloco de critérios, além dos índices de valor $\left(V_{\text {educ }}, V_{\text {tur }}, V_{\text {prot }}\right)$ obtidos, encontram-se expressos nas tabelas 1-3. Salienta-se, aqui, que aqueles lugares listados são os mais característicos e representativos de cada um dos quatro principais contextos geológicos do município de Caçapava do Sul: (1) embasamento e bacias vulcanossedimentares metamorfizadas; (2) bacias vulcanossedimentares do Neoproterozoico, não-metamórficas; (3) granitoides; e (4) bacias sedimentares do Paleozoico inferior, com vulcanismo associado. Esses quatro contextos (Tabs. 1-3; fig. 1) contemplam cinco das sete fases (explanadas acima) de evolução geológica da região, uma vez que as duas últimas fases (soerguimentos diferenciais e desenho das formas de relevo) apenas impõem relações de contato e feições geomorfológicas sobre rochas já contempladas nos quatro contextos geológicos. É igualmente importante salientar que esta avaliação reflete a experiência dos pesquisadores responsáveis por este trabalho; outros grupos de pesquisa podem identificar outros geossítios, agrupá-los ou avaliá-los de forma diferente, assim como novos locais de interesse podem vir a se destacar com o avanço das pesquisas e mapeamentos geológicos no município.

De uma maneira geral, os escores para os diferentes blocos de critérios (Tabs. 1-2), assim como os índices de valor resultantes (Tab. 3), são significativamen- te maiores para grandes áreas complexas e formas de relevo destacadas, e menores para afloramentos simples, pontuais, que, via de regra, apenas registram um processo ou um tipo de rocha, especialmente os cortes de estrada (geossítios 08, 14, 17, 31, 32, 34 e 36 nas tabelas e na fig. 1). Esse resultado era esperado, uma vez que grandes áreas complexas têm maior probabilidade de exibir feições mais diversificadas, envolvendo geologia, tectônica e geomorfologia, além de possuírem, em geral, melhor visibilidade e destaque na paisagem. Cinco afloramentos simples, no entanto, representativos de todos os contextos geológicos, merecem destaque do ponto de vista do interesse didático, com escore alto para o bloco geocientífico, alta fragilidade e um valor educativo $\left(V_{\text {educ }}\right)$ relativamente elevado: (a) a cascata Neto Rodrigues, onde afloram granitoides bandados com os zircões mais antigos da região $(2,48 \mathrm{Ga}$, Remus et al., 1996); (b) as pillow-lavas arroio Mudador, evidências de vulcanismo subaquático em ambiente oceânico no Neoproterozoico (Chaves et al., 2011); (c) a cascata do arroio Pessegueiro, na Serra de Santa Bárbara, cujos riolitos (Formação Acampamento Velho) possuem estruturas de fluxo dobradas excepcionalmente didáticas (Zerfass \& Almeida, 1997), além de estruturas tectônicas rúpteis; (d) a cascata do Salso, com suas paredes de granito, no arroio de mesmo nome, muito próxima da cidade mas com acessibilidade precária para veículos sem tração especial; e (e) o afloramento do arroio Carajá, por sua alta geodiversidade e raridade, com lavas basálticas em corda e tubo, arenitos conglomeráticos, peperitos (interação lava/sedimento úmido), diques clásticos e amígdalas alongadas preenchidas por silicatos e carbonatos diversos (Petry \& Almeida, 2005).

Entretanto, os destaques do estudo são, de fato, as grandes áreas complexas, adequadas para estratégias diversificadas de geoconservação, como proteção legal em UC, educação geocientífica, desenvolvimento do turismo e prática de esportes de aventura na natureza (trilhas, mountain bike, escalada em rocha, caiaque, voo livre, etc.). Os maiores valores educativo e turístico (Tab. 3) foram obtidos para as Pedras das Guaritas, conjuntos de cerros ruiniformes (Fig. 2A) desenhados por abrasão eólica e pluvial sobre uma sucessão de rochas aluviais e fluviais da Formação Guaritas, do Paleozoico inferior (Paim et al., 2000). Aquele geossítio destaca-se nos critérios geocientíficos de representatividade, raridade e integridade, constituindo um excepcional lugar para o ensino e a difusão do conhecimento relacionado aos seguintes tópicos: (a) sedimentologia e estratigrafia; (b) tectônica rúptil; (c) instalação, inversão e exposição de bacias; (d) processos geomorfológicos em clima seco; (e) mudanças climáticas; e (f) ecologia. Por todas essas características, o geossítio foi incluído na lista SIGEP (sítios geológicos e paleobiológicos do Brasil, iniciativa da Universidade de Brasília) através do trabalho de Paim et al. (2010). As Pedras das Guaritas ainda se destacam nos critérios culturais, não apenas pela profunda identificação da região de Caçapava do 
Sul com o termo "Guaritas", mas também pela utilização de suas paisagens como cenário no recente filme "Valsa para Bruno Stein", de 2007, dirigido por Paulo Nascimento. Nos blocos estético e econômico, as Pedras das Guaritas também obtiveram resultados significativos, por sua visibilidade excelente, destaque na paisagem e pelo fato de que, se bem trabalhada turisticamente, a área constitui certamente um atrativo geoturístico de nível internacional. Dois estabelecimentos de vocação turística destacam-se na extensa área das Pedras das Guaritas: o terreno da Associação de Moradores, com um centro de visitação; e a Fazenda São João, empreendimento de turismo rural com grutas de abrasão eólica em seu interior.

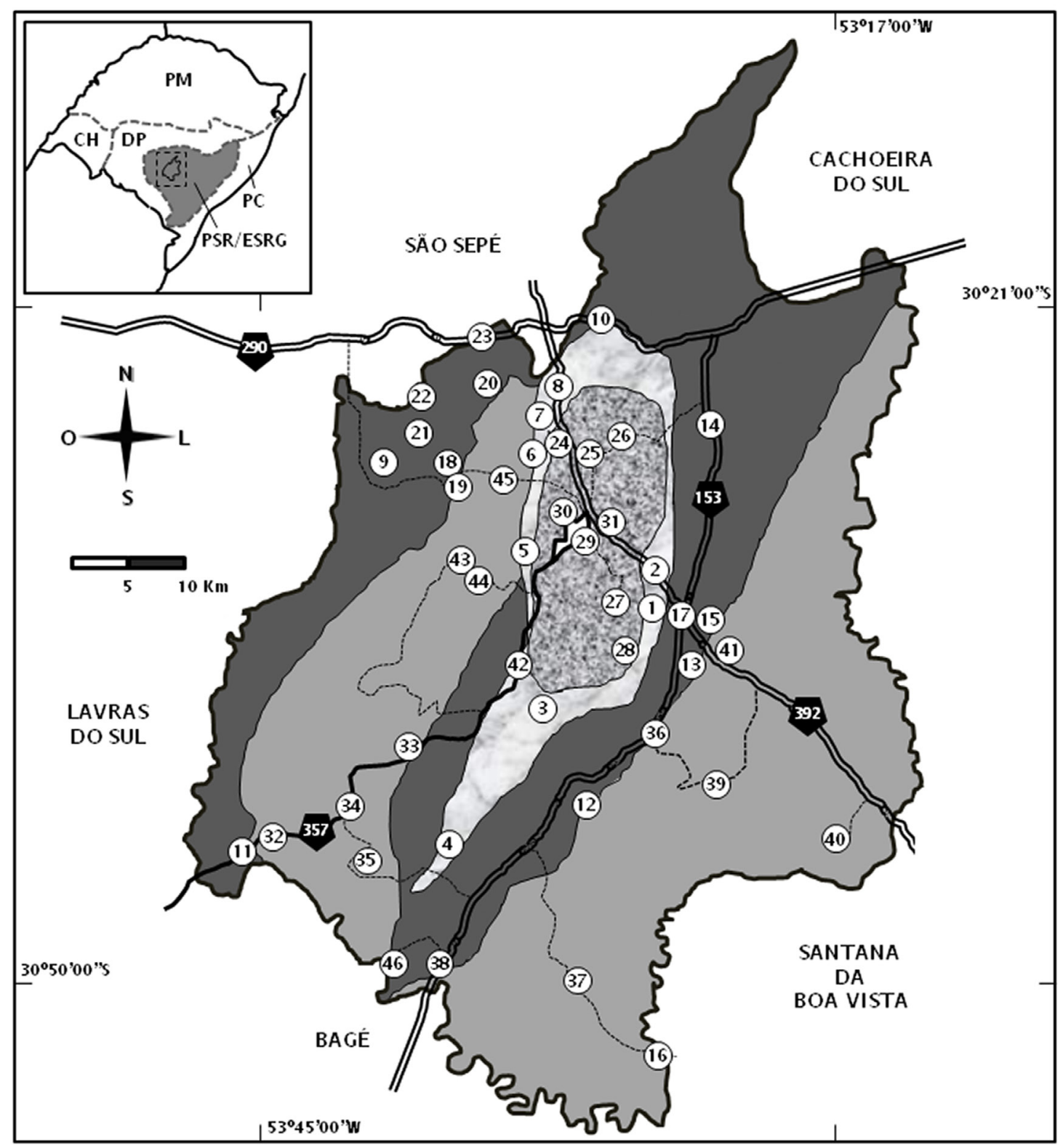

COIITEXTOS GEOLÓGICOS
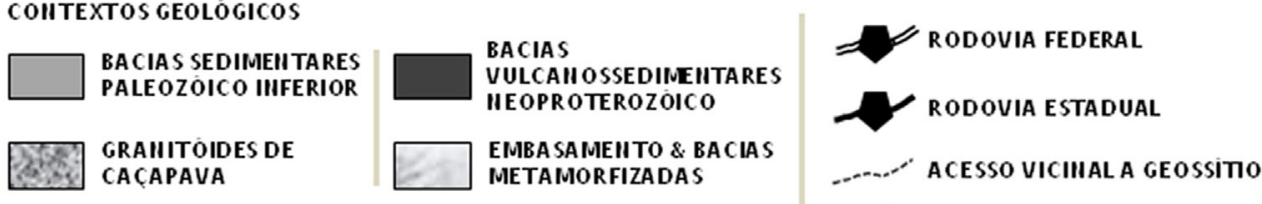

(16) GEOSSITIOS- IIUMERAdOS COMFORME TABELA I

ZOIIA URBAIIA

Figura 1. Mapa esquemático do Município de Caçapava do Sul, ilustrando seus principais contextos geológicos e a localização dos 46 geossítios inventariados e avaliados neste trabalho; a numeração dos geossítios segue as tabelas de valoração (Tabs. 1-3); no pequeno mapa de situação geral, no canto superior esquerdo, estão ilustradas as regiões geomorfológicas do Rio Grande do Sul: PM - Planalto Meridional; DP - Depressão Periférica; CH - Cuesta do Haedo; PC - Planície Costeira; a área destacada em cinza escuro, em cujo interior se encontra o contorno do município de Caçapava do Sul, corresponde ao Planalto Sul-rio-grandense ou Escudo Sul-rio-grandense (PSR/ESRG). 
Tabela 1. Notas atribuídas aos 46 geossítios em avaliação, agrupados nos quatro contextos geológicos, para os critérios dos blocos geocientífico, ecológico e cultural, os escores médios resultantes e o fator ecológico $\left(F_{\text {ecol }}\right)$ calculado; as coordenadas geográficas dos lugares encontram-se listadas na tabela 3 e representadas graficamente na figura 1.

\begin{tabular}{|c|c|c|c|c|c|c|c|c|c|c|c|c|c|c|}
\hline \multirow[t]{2}{*}{ Contexto } & \multirow[t]{2}{*}{ Geossítio } & \multicolumn{5}{|c|}{ Bloco geocientífico } & \multirow{2}{*}{$\begin{array}{l}\text { MÉDIA } \\
\text { CIENT }\end{array}$} & \multicolumn{2}{|l|}{ Bloco ecológico } & \multirow{2}{*}{$\begin{array}{l}\text { MÉDIA } \\
\text { ECOL }\end{array}$} & \multirow[t]{2}{*}{ Fecol } & \multicolumn{2}{|c|}{ Bloco cultural } & \multirow{2}{*}{$\begin{array}{l}\text { MÉDIA } \\
\text { CULT }\end{array}$} \\
\hline & & História geológica & $\begin{array}{l}\text { Representa- } \\
\text { tividade }\end{array}$ & $\begin{array}{l}\text { Geodiversi- } \\
\text { dade }\end{array}$ & Raridade & Integridade & & $\begin{array}{l}\text { Estruturação de Status } \\
\text { habitats }\end{array}$ & $s$ proteção & & & História & $\begin{array}{l}\text { Arte / } \\
\text { Cultura }\end{array}$ & \\
\hline \multirow{8}{*}{ 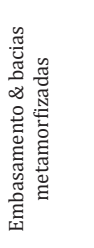 } & 01 - Cascata Neto Rodrigues & 3 & 8 & 2 & 8 & 8 & 5,8 & 5 & 9 & 7 & 0,56 & 1 & 1 & 1 \\
\hline & 02 - Área das Caieiras & 3,5 & 9 & 6 & 9 & 2 & 5,9 & 1 & 1 & 1 & 1 & 1 & 1 & 1 \\
\hline & 03 - Seção arroio Passo Feio & 2 & 9 & 5 & 5 & 8 & 5,8 & 2 & 9 & 5,5 & 0,22 & 1 & 1 & 1 \\
\hline & 04 - Arroio Mudador - pillow lavas & 2 & 9 & 3 & 9 & 8 & 6,2 & 4 & 9 & 6,5 & 0,44 & 1 & 1 & 1 \\
\hline & 05 - Cerro dos Andradas & 4 & 9 & 5 & 6 & 4 & 5,6 & 5 & 4 & 4,5 & 1,25 & 1 & 1 & 1 \\
\hline & 06 - Cerros Andradas Norte & 3 & 7 & 4,5 & 6 & 8 & 5,7 & 5 & 4 & 4,5 & 1,25 & 1 & 1 & 1 \\
\hline & 07 - Pedreira de talco & 2 & 8 & 2,5 & 9 & 2 & 4,7 & 1 & 1 & 1 & 1 & 1 & 1 & 1 \\
\hline & 08 - Dobra recumbente BR-392 & 2 & 7 & 2 & 8 & 8 & 5,4 & 1 & 1 & 1 & 1 & 1 & 1 & 1 \\
\hline \multirow{15}{*}{ 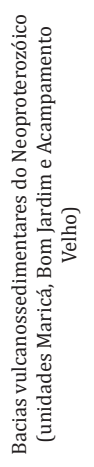 } & 09 - Passo da Promessa & 1,5 & 5 & 2 & 3 & 8 & 3,9 & 4 & 9 & 6,5 & 0,44 & 1 & 1 & 1 \\
\hline & 10 - Passo das Ilhas BR-290 & 1,5 & 5 & 2,5 & 5 & 8 & 4,4 & 4 & 9 & 6,5 & 0,44 & 1 & 1 & 1 \\
\hline & 11 - Pedreira de lamprófiros Sta. Fé & 1,5 & 7 & 2 & 8 & 3 & 4,3 & 2 & 1 & 1,5 & 2 & 1 & 1 & 1 \\
\hline & 12 - Cerro dos Martins & 6 & 7 & 7 & 6 & 5 & 6,2 & 5 & 4 & 4,5 & 1,25 & 1 & 1 & 1 \\
\hline & 13 - Cerro da Angélica & 5,5 & 6,5 & 5,5 & 6 & 6 & 5,9 & 5 & 4 & 4,5 & 1,25 & 1 & 1 & 1 \\
\hline & 14 - Cortes BR-153 arroio Lajeado & 3 & 4 & 3,5 & 3 & 7 & 4,1 & 1 & 1 & 1 & 1 & 1 & 1 & 1 \\
\hline & 15 - Pedreira argilitos BellaGres & 3 & 4 & 3,5 & 3 & 3 & 3,3 & 1 & 1 & 1 & 1 & 1 & 1 & 1 \\
\hline & 16 - Minas do Camaquã & 4,5 & 9 & 6 & 9 & 3 & 6,3 & 1 & 1 & 1 & 1 & 4 & 3 & 3,5 \\
\hline & 17 - Entroncamento BR-153/BR-392 & 1,5 & 5 & 1,5 & 3 & 5 & 3,2 & 1 & 1 & 1 & 1 & 1 & 1 & 1 \\
\hline & 18 - Cerro do Bugio & 4,5 & 9 & 6 & 6 & 9 & 6,9 & 7 & 4 & 5,5 & 1,75 & 1 & 1 & 1 \\
\hline & 19 - Cascata do Pessegueiro & 3 & 8 & 4,5 & 7 & 8 & 6,1 & 5 & 9 & 7 & 0,56 & 1 & 1 & 1 \\
\hline & 20 - Cerro do Espinilho & 3,5 & 4 & 3,5 & 6 & 9 & 5,2 & 7 & 4 & 5,5 & 1,75 & 1 & 1 & 1 \\
\hline & 21 - Cerro dos Machados & 3,5 & 4 & 3,5 & 6 & 8,5 & 5,1 & 7 & 4 & 5,5 & 1,75 & 1 & 1 & 1 \\
\hline & 22 - Cerro dos Nascimentos & 3,5 & 4,5 & 3,5 & 6 & 8,5 & 5,2 & 6 & 2 & 4 & 3 & 1 & 1 & 1 \\
\hline & 23 - Mirador Espinilho BR-290 & 3,5 & 4 & 3,5 & 6 & 9 & 5,2 & 1 & 1 & 1 & 1 & 1 & 1 & 1 \\
\hline \multirow{8}{*}{ 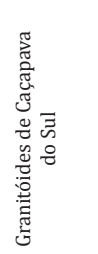 } & 24 - Matacões vila Frigorífico & 4,5 & 5,5 & 4,5 & 5 & 5 & 4,9 & 4 & 1 & 2,5 & 4 & 1 & 1 & 1 \\
\hline & 25 - Cerro do Perau & 4,5 & 9 & 5,5 & 6 & 8 & 6,6 & 9 & 4 & 6,5 & 2,25 & 1 & 1 & 1 \\
\hline & 26 - Cerro do Reginaldo & 4,5 & 9 & 5,5 & 6 & 7 & 6,4 & 8 & 4 & 6 & 2 & 1 & 1 & 1 \\
\hline & 27 - Cascata do Salso & 3 & 7 & 4 & 6 & 7 & 5,4 & 4 & 8 & 6 & 0,50 & 1 & 1 & 1 \\
\hline & 28 - Matacões Capela Santo Antônio & 4 & 4 & 3 & 5 & 7 & 4,6 & 3 & 1 & 2 & 3 & 1 & 1 & 1 \\
\hline & 29 - Matacões CORSAN & 2 & 4 & 3 & 5 & 3 & 3,4 & 1 & 1 & 1 & 1 & 1 & 1 & 1 \\
\hline & 30 - Chácara do Forte & 4 & 5,5 & 4,5 & 5,5 & 7 & 5,3 & 3 & 3 & 3 & 1 & 1 & 1 & 1 \\
\hline & 31 - Paredão BR-392 & 3 & 4 & 4 & 5 & 6,5 & 4,5 & 1 & 1 & 1 & 1 & 1 & 1 & 1 \\
\hline \multirow{15}{*}{ 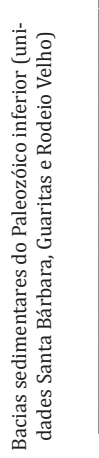 } & 32 - Cortes Santa Fé RS-357 & 1,5 & 5 & 4,5 & 3 & 7 & 4,2 & 1 & 1 & 1 & 1 & 1 & 1 & 1 \\
\hline & 33 - Granja Don Augusto RS-357 & 2,5 & 4 & 3,5 & 4 & 7 & 4,2 & 2 & 1 & 1,5 & 2 & 1 & 1 & 1 \\
\hline & 34 - Corte Altos da Serra RS-357 & 2 & 4 & 5 & 3 & 7 & 4,2 & 1 & 1 & 1 & 1 & 1 & 1 & 1 \\
\hline & 35 - Arroio Carajá & 3 & 7,5 & 6 & 9 & 6,5 & 6,4 & 1 & 8 & 4,5 & 0,13 & 1 & 1 & 1 \\
\hline & 36 - Corte Guaritas BR-153 tenda & 1,5 & 3 & 3,5 & 3 & 7 & 3,6 & 1 & 1 & 1 & 1 & 1 & 1 & 1 \\
\hline & 37 - Pedras das Guaritas & 4 & 10 & 8,5 & 9 & 9,5 & 8,2 & 8 & 6 & 7 & 1,33 & 1 & 7 & 4 \\
\hline & 38 - Mirador Guaritas BR-153 & 3,5 & 9,5 & 8 & 8 & 9,5 & 7,7 & 1 & 1 & 1 & 1 & 1 & 1 & 1 \\
\hline & 39 - Pedra da Guarda Velha & 3,5 & 4 & 5,5 & 6 & 6,5 & 5,1 & 6 & 6 & 6 & 1 & 5 & 5 & 5 \\
\hline & 40 - Gruta da Varzinha & 2 & 5 & 4,5 & 6 & 9 & 5,3 & 7 & 5 & 6 & 1,40 & 1 & 1 & 1 \\
\hline & 41 - Toca das Carretas & 3 & 4,5 & 5,5 & 6 & 9 & 5,6 & 7 & 5 & 6 & 1,40 & 1 & 5 & 3 \\
\hline & 42 - Mirador Sa. do Segredo RS-357 & 6 & 8,5 & 8,5 & 8 & 9 & 8 & 1 & 1 & 1 & 1 & 1 & 1 & 1 \\
\hline & 43 - Pedra do Segredo & 6 & 9 & 10 & 8 & 7 & 8 & 8 & 6 & 7 & 1,33 & 1 & 5 & 3 \\
\hline & 44 - Pedra do Leão & 5,5 & 8,5 & 8,5 & 8 & 8,5 & 7,8 & 8 & 6 & 7 & 1,33 & 1 & 4 & 2,5 \\
\hline & 45 - Passo do Meio - Ar. Lanceiros & 1,5 & 5 & 6 & 3 & 7 & 4,5 & 4 & 9 & 6,5 & 0,44 & 1 & 1 & 1 \\
\hline & 46 - Rincão da Tigra & 5,5 & 6,5 & 7,5 & 7 & 8 & 6,9 & 7 & 5 & 6 & 1,40 & 1 & 1 & 1 \\
\hline
\end{tabular}

A Serra do Segredo (Borba et al., 2011), situada muito próxima à cidade de Caçapava do Sul, possui dois geossítios de altos valores educativo e turístico (Tab. 3): a Pedra do Segredo, em cujo acesso há um pequeno parque municipal, que no entanto não constitui UC (acesso a R\$3,00); e a Pedra do Leão, situada no interior de um camping privado chamado 'Galpão de Pedra' (permanência a R \$15,00 por dia). As rochas ali expostas registram a seção mais jovem da Formação Santa Bárbara, também do Paleozoico inferior, depositada por canais fluviais entrelaçados de carga cascalhosa (Borba \& Mizusaki, 2003). Os cerros ruiniformes (Fig. 2B), com perfil arredondado e paredes verticais que acompanham a direção das estruturas tectônicas rúpteis, também são o registro da alternância de climas mais secos e mais úmidos no Quaternário. Assim como as Pedras das Guaritas, a Pedra do Segredo e a Pedra do Leão destacam- -se em todos os critérios geocientíficos, e ainda em sua disponibilidade de habitats para espécies endêmicas e ameaçadas. Ainda podem ser ressaltados seus atributos estéticos, por sua substancial visibilidade e destaque na paisagem, além do fato de permitirem a visualização (conforme explicado anteriormente) de outras unidades rochosas e outros contextos da região estudada. Nos critérios integridade, degradação e intensidade de uso, a Pedra do Segredo e a Pedra do Leão receberam notas relativamente mais baixas (ainda que a Pedra do Leão esteja muito melhor preservada em termos ecológicos), o que levou em conta os seguintes fatores: (a) a recente (entre 2008 e 2011) retomada de trabalhos de pesquisa mineral e construção de novos acessos a alvos de futura mineração no Cerro dos Andradas, alguns dos quais estão a menos de $700 \mathrm{~m}$ dos cerros estudados; e (b) a implantação de pelo menos um grande talhão de 
Tabela 2. Notas atribuídas aos 46 geossítios em avaliação, agrupados nos quatro contextos geológicos, para os critérios dos blocos estético, econômico e de uso potencial, bem como os escores médios resultantes; as coordenadas geográficas dos lugares encontram-se listadas na tabela 3 e representadas graficamente na figura 1.

\begin{tabular}{|c|c|c|c|c|c|c|c|c|c|c|c|c|c|c|}
\hline \multirow[t]{2}{*}{ Contexto } & \multirow[t]{2}{*}{ Geossítio } & \multicolumn{2}{|c|}{ Bloco Estético } & \multirow{2}{*}{$\begin{array}{l}\text { MÉDIA } \\
\text { ESTET }\end{array}$} & \multicolumn{3}{|c|}{ Bloco econômico } & \multirow{2}{*}{$\begin{array}{l}\text { MÉDIA } \\
\text { ECON }\end{array}$} & \multicolumn{5}{|c|}{ Bloco de uso potencial } & \multirow{2}{*}{$\begin{array}{l}\text { MÉDIA } \\
\text { USO }\end{array}$} \\
\hline & & $\begin{array}{l}\text { Visibi- } \\
\text { lidade }\end{array}$ & $\begin{array}{l}\text { Destaque } \\
\text { paisagem }\end{array}$ & & Visitantes & Nível & $\begin{array}{c}\text { Proteção } \\
\text { oficial }\end{array}$ & & $\begin{array}{c}\text { Intensidade } \\
\text { de uso }\end{array}$ & $\begin{array}{c}\text { Degra- } \\
\text { dação }\end{array}$ & $\begin{array}{c}\text { Fragili- } \\
\text { dade }\end{array}$ & $\begin{array}{l}\text { Acessibi- } \\
\text { lidade }\end{array}$ & $\begin{array}{l}\text { Mudanças } \\
\text { aceitáveis }\end{array}$ & \\
\hline \multirow{8}{*}{ 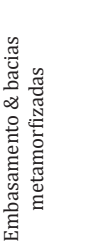 } & 01 - Cascata Neto Rodrigues & 1 & 1 & 1 & 1 & 1 & 10 & 4 & 8 & 8 & 6 & 7 & 3 & 6,4 \\
\hline & 02 - Área das Caieiras & 5 & 6 & 5,5 & 1 & 3 & 10 & 4,7 & 1 & 1 & 5 & 9,5 & 8 & 4,9 \\
\hline & 03 - Seção arroio Passo Feio & 1 & 1 & 1 & 1 & 1 & 10 & 4 & 8 & 7 & 5 & 2 & 4 & 5,2 \\
\hline & 04 - Arroio Mudador - pillow lavas & 1 & 1 & 1 & 1 & 3 & 10 & 5 & 8 & 8 & 9 & 2 & 1 & 5,6 \\
\hline & 05 - Cerro dos Andradas & 7 & 6 & 6,5 & 1 & 1 & 10 & 4 & 3 & 3 & 5 & 7 & 5 & 4,6 \\
\hline & 06 - Cerros Andradas Norte & 5 & 6 & 5,5 & 1 & 1 & 10 & 4 & 6 & 6 & 5 & 6 & 3 & 5,2 \\
\hline & 07 - Pedreira de talco & 1 & 1 & 1 & 1 & 1 & 10 & 4 & 1 & 1 & 4 & 8 & 7 & 4,2 \\
\hline & 08 - Dobra recumbente BR-392 & 1 & 1 & 1 & 1 & 1 & 10 & 4 & 5 & 7 & 9 & 9,5 & 2 & 6,5 \\
\hline \multirow{15}{*}{ 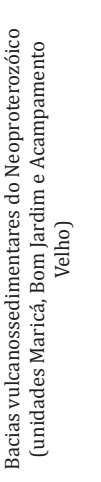 } & 09 - Passo da Promessa & 1 & 1 & 1 & 1 & 1 & 10 & 4 & 8 & 9 & 5 & 3 & 4 & 5,8 \\
\hline & 10 - Passo das Ilhas BR-290 & 1 & 1 & 1 & 1 & 1 & 10 & 4 & 5 & 7 & 6 & 9 & 2 & 5,8 \\
\hline & 11 - Pedreira de lamprófiros Sta. Fé & 1 & 1 & 1 & 1 & 1 & 10 & 4 & 3 & 2 & 4 & 8 & 7 & 4,8 \\
\hline & 12 - Cerro dos Martins & 7 & 6 & 6,5 & 1 & 1 & 10 & 4 & 4 & 3 & 4 & 7 & 2 & 4 \\
\hline & 13 - Cerro da Angélica & 10 & 8 & 9 & 2 & 3 & 10 & 5 & 6 & 4 & 4 & 8 & 2 & 4,8 \\
\hline & 14 - Cortes BR-153 arroio Lajeado & 1 & 1 & 1 & 1 & 1 & 10 & 4 & 5 & 8 & 4 & 9 & 2 & 5,6 \\
\hline & 15 - Pedreira argilitos BellaGres & 1 & 1 & 1 & 1 & 1 & 10 & 4 & 3 & 3 & 4 & 8,5 & 7 & 5,1 \\
\hline & 16 - Minas do Camaquã & 5 & 4 & 4,5 & 2 & 3 & 10 & 5 & 2 & 1 & 4 & 4 & 7 & 3,6 \\
\hline & 17 - Entroncamento BR-153/BR-392 & 1 & 1 & 1 & 1 & 1 & 10 & 4 & 5 & 7 & 4 & 9 & 2 & 5,4 \\
\hline & 18 - Cerro do Bugio & 9 & 8 & 8,5 & 1 & 3 & 10 & 4,7 & 9 & 8 & 6 & 3 & 2 & 5,6 \\
\hline & 19 - Cascata do Pessegueiro & 1 & 2 & 1,5 & 1,5 & 3 & 10 & 4,8 & 8 & 8 & 8 & 3 & 3 & 6 \\
\hline & 20 - Cerro do Espinilho & 8 & 7 & 7,5 & 1 & 1 & 10 & 4 & 8 & 8 & 4 & 3 & 2 & 5 \\
\hline & 21 - Cerro dos Machados & 8 & 7 & 7,5 & 1 & 1 & 10 & 4 & 8 & 7 & 4 & 3 & 2 & 4,8 \\
\hline & 22 - Cerro dos Nascimentos & 5 & 6 & 5,5 & 1 & 1 & 10 & 4 & 8 & 7 & 4 & 3 & 2 & 4,8 \\
\hline & 23 - Mirador Espinilho BR-290 & 1 & 7 & 4 & 3 & 1 & 10 & 4,7 & 3 & 2 & 6 & 9 & 8 & 5,6 \\
\hline \multirow{8}{*}{ 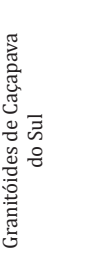 } & 24 - Matacões vila Frigorífico & 2 & 4 & 3 & 1 & 2 & 10 & 4,3 & 4 & 4 & 5 & 9 & 5 & 5,4 \\
\hline & 25 - Cerro do Perau & 9 & 8 & 8,5 & 1 & 6 & 10 & 5,7 & 9 & 8 & 9 & 7 & 2 & 7 \\
\hline & 26 - Cerro do Reginaldo & 9 & 8 & 8,5 & 1 & 5 & 10 & 5,3 & 6 & 3 & 9 & 6 & 3 & 5,4 \\
\hline & 27 - Cascata do Salso & 1 & 2 & 1,5 & 3 & 3 & 10 & 5,3 & 5 & 5 & 7 & 6 & 4 & 5,4 \\
\hline & 28 - Matacões Capela Santo Antônio & 1 & 3 & 2 & 1 & 1 & 10 & 4 & 8 & 8 & 5 & 5 & 4 & 6 \\
\hline & 29 - Matacões CORSAN & 1 & 2 & 1,5 & 4 & 1 & 10 & 5 & 5 & 2 & 5 & 10 & 9 & 6,2 \\
\hline & 30 - Chácara do Forte & 1 & 4 & 2,5 & 3 & 2 & 10 & 5 & 6 & 6 & 5 & 9 & 4 & 6 \\
\hline & 31 - Paredão BR-392 & 1 & 2 & 1,5 & 1 & 1 & 10 & 4 & 5 & 8 & 4 & 9,5 & 6 & 6,5 \\
\hline \multirow{15}{*}{ 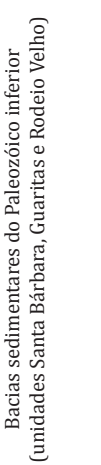 } & 32 - Cortes Santa Fé RS-357 & 1 & 1 & 1 & 1 & 1 & 10 & 4 & 5 & 8 & 4 & 8 & 2 & 5,4 \\
\hline & 33 - Granja Don Augusto RS-357 & 2 & 3 & 2,5 & 1 & 1 & 10 & 4 & 9 & 7 & 4 & 8,5 & 4 & 6,5 \\
\hline & 34 - Corte Altos da Serra RS-357 & 1 & 1 & 1 & 1 & 1 & 10 & 4 & 5 & 8 & 7 & 8 & 2 & 6 \\
\hline & 35 - Arroio Carajá & 1 & 2 & 1,5 & 1 & 1 & 10 & 4 & 4 & 5 & 9 & 3 & 5 & 5,2 \\
\hline & 36 - Corte Guaritas BR-153 tenda & 1 & 1 & 1 & 1,5 & 1 & 10 & 4,2 & 5 & 8 & 4 & 8,5 & 2 & 5,5 \\
\hline & 37 - Pedras das Guaritas & 9 & 9 & 9 & 4 & 9 & 10 & 7,7 & 9 & 7 & 7 & 4 & 2 & 5,8 \\
\hline & 38 - Mirador Guaritas BR-153 & 1 & 9 & 5 & 1 & 9 & 10 & 6,7 & 3 & 2 & 6 & 8 & 8 & 5,4 \\
\hline & 39 - Pedra da Guarda Velha & 4 & 4 & 4 & 4 & 3 & 10 & 5,7 & 6 & 4 & 5 & 5 & 6 & 5,2 \\
\hline & 40 - Gruta da Varzinha & 1 & 1 & 1 & 1 & 2 & 10 & 4,3 & 9 & 9 & 9 & 2 & 2 & 6,2 \\
\hline & 41 - Toca das Carretas & 4 & 4 & 4 & 1 & 2 & 10 & 4,3 & 9 & 9 & 8 & 9 & 2 & 7,4 \\
\hline & 42 - Mirador Sa. do Segredo RS-357 & 1 & 8 & 4,5 & 1 & 8 & 10 & 6,3 & 3 & 2 & 6 & 9,5 & 8 & 5,7 \\
\hline & 43 - Pedra do Segredo & 8 & 9 & 8,5 & 6 & 8 & 10 & 8 & 5 & 4 & 9 & 6 & 3 & 5,4 \\
\hline & 44 - Pedra do Leão & 8 & 9 & 8,5 & 4 & 8 & 10 & 7,3 & 8 & 8 & 7 & 6,5 & 2 & 6,3 \\
\hline & 45 - Passo do Meio - Ar. Lanceiros & 1 & 1 & 1 & 1 & 1 & 10 & 4 & 8 & 5 & 8 & 4 & 4 & 5,8 \\
\hline & 46 - Rincão da Tigra & 6 & 8 & 7 & 1 & 6 & 10 & 6 & 9 & 8 & 6 & 5 & 3 & 6,2 \\
\hline
\end{tabular}

cultivo de eucalipto para a indústria de papel e celulose junto à estrada vicinal que dá acesso aos geossítios, cerca de um quilômetro a leste da Pedra do Leão. Também por isso esses dois locais possuem valores de necessidade de proteção $\left(V_{\text {prot }}\right)$ entre os maiores deste estudo (Tab. 3).

Ainda dentro do contexto das bacias sedimentares do Paleozoico inferior, merecem referência outros três geossítios. A Toca das Carretas, com acesso bastante facilitado a partir da BR-392, registra arenitos e conglomerados organizados, com estratificações cruzadas, em uma gruta (ou "toca") semelhante à da Pedra do Segredo, inclusive com alteração alveolar (tafoni) superimposta. Esse local, situado na face leste de um cerro com encostas suaves, com abundante mata nativa associada, foi utilizado como cenário para uma das passagens do filme "Anahy de las Misiones", de 1997, dirigido por Sérgio Silva, motivo pelo qual foi bem avaliado no critério arte/cultura. A área do Rincão da Tigra, situada no extremo sul do município, constitui-se de um conjunto de cerros entremeados por vales fluviais encaixados, com conglomerados aluviais muito grossos e desorganizados, além de rochas vulcânicas básicas, por vezes silicificadas. Suas elevações, além de possuírem boa visibilidade a partir da rodovia BR-153, permitem, para quem se posiciona em seus pontos culminantes, uma excelente vista para outras áreas como as Pedras das Guaritas, além de locais de destaque nos municípios de Bagé e Lavras do Sul (Rincão do Inferno e Casa de Pedra). Por fim, outro geossítio de significado cultural importante é a Pedra da Guarda Velha, inserida na sede campestre de um "piquete de lançadores", entidade vinculada ao tradicionalismo sul-rio-grandense. Nesse mesmo local, há um marco comemorativo, feito 
em concreto, que registra a antiga fronteira entre os domínios dos reinos de Portugal e Espanha na América do Sul, estabelecida pelos termos do Tratado de Santo Ildefonso, em 1777, e que seccionava o atual Município de Caçapava do Sul. Tal atributo histórico eleva o índice de valor educativo $\left(V_{\text {educ }}\right)$ da Pedra da Guarda Velha (Tab. 3).

Dois geossítios representativos dos granitoides de Caçapava do Sul, posicionados e cristalizados em torno de 550 Ma (Sartori \& Kawashita, 1985; Leite et al., 1995) ao longo de importante zona de cisalhamento vinculada à reativação da sutura de Caçapava, merecem referência por seus altos valores educativo e turístico. 0 Cerro do Perau, situado próximo à BR-392, a poucos quilômetros do acesso à cidade, constitui-se de um conjunto de três cristas alongadas na direção NW-SE, separadas por estruturas tectônicas (falhas) de mesma direção, ao longo das quais se desenvolveram cursos d'água com abundante vegetação ripária (Fig. 2C). Já o Cerro do Reginaldo, situado mais a leste em relação ao Cerro do Perau (Fig. 1), com acesso por estradas vicinais, também é alongado na direção NW-SE e, em sua porção média, é cortado por uma zona de alta deformação rúptil E-W, com alta densidade de fraturas. Naquelas elevações, que chegam a $450 \mathrm{~m}$ de altitude, afloram sienogranitos dominantes, com monzogranitos subordinados (UFRGS, 1998), na forma de matacões de formato irregular, lajeados intensamente fraturados e pavimentos pedregosos. Além de serem muito representativos da atividade plutônica na região e dos eventos posteriores de soerguimento tectônico e desenvolvimento de formas de relevo alongadas, ambos os cerros possuem pavimentos com blocos soltos de granito, os quais são ocupados por um ecossistema muito rico em biodiversidade, incluindo bromélias, cactáceas, serpentes, lagartos, aranhas e escorpiões. Por isso, destacam-se nos blocos geocientífico e ecológico (Tab. 1), mesmo que haja atividade de pecuária nas suas porções de topo. O Cerro do Reginaldo, sobretudo em sua terminação sudeste, foi objeto de plantio de talhões de eucalipto (Fig. 2D), que são muito prejudiciais ao fazerem sombra aos organismos rupestres, adaptados à maior incidência de sol durante o dia. Além disso, há no mesmo cerro o passivo ambiental de uma pedreira de granito desativada. Esses elementos de degradação ambiental diminuem sua nota no atributo integridade, elevando o valor de necessidade de proteção $\left(V_{\text {prot }}\right)$ relacionado ao geossítio.

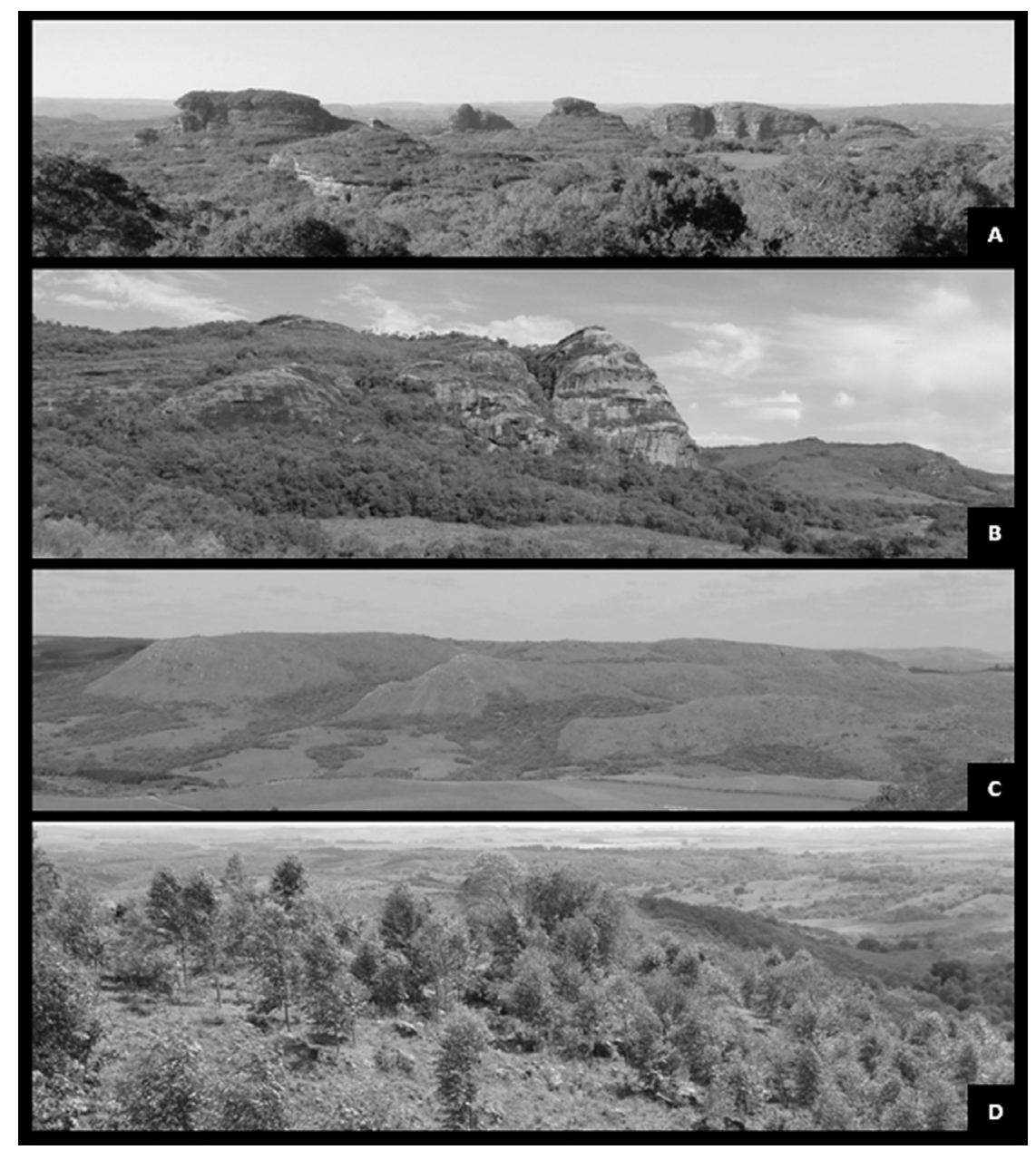

Figura 2. Aspectos mais significativos do patrimônio geológico de Caçapava do Sul: (A) a paisagem mais clássica do geossítio Pedras das Guaritas, que possui os mais expressivos índices de valor educativo e turístico no âmbito deste estudo; (B) um dos mais belos (e menos conhecidos) ângulos da Pedra do Segredo, vista de norte para sul, à tarde, exibindo sua forma arredondada e suas paredes escavadas pela abrasão eólica e pluvial; (C) as três cristas graníticas formadoras do Cerro do Perau, em fotografia obtida pela manhã desde o Cerro do Reginaldo (de leste para oeste); (D) exemplares jovens de eucalipto em talhão de silvicultura implantado na porção leste do Cerro do Reginaldo, com severo prejuízo às espécies existentes junto aos matacões e lajeados graníticos do local. 
Tabela 3. Geossítios avaliados, agrupados nos quatro contextos geológicos, coordenadas geográficas e índices de valor educativo (Veduc), turístico (Vtur) e de necessidade de proteção (Vprot) obtidos através da aplicação das fórmulas detalhadas no texto, desenvolvidas por Fassoulas et al. (2012).

\begin{tabular}{|c|c|c|c|c|c|c|}
\hline \multirow[t]{2}{*}{ Contexto } & \multirow[t]{2}{*}{ Geossítio } & \multicolumn{2}{|c|}{ Coordenadas } & \multicolumn{3}{|c|}{ Valores } \\
\hline & & Lat & Long & Veduc & Vtur & Vprot \\
\hline \multirow{8}{*}{ 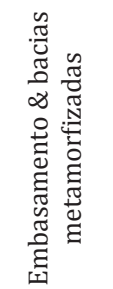 } & 01 - Cascata Neto Rodrigues & $30^{\circ} 34^{\prime} 43^{\prime \prime}$ & $53^{\circ} 24^{\prime} 30^{\prime \prime}$ & 4,12 & 2,68 & 3,12 \\
\hline & 02 - Área das Caieiras - indústrias de cal & $30^{\circ} 32^{\prime} 36^{\prime \prime}$ & $53^{\circ} 25^{\prime} 22^{\prime \prime}$ & 3,86 & 4,31 & 5,30 \\
\hline & 03 - Seção arroio Passo Feio & $30^{\circ} 38^{\prime} 15^{\prime \prime}$ & $53^{\circ} 28^{\prime} 50^{\prime \prime}$ & 3,82 & 2,44 & 3,01 \\
\hline & 04 - Arroio Mudador - pillow lavas & $30^{\circ} 46^{\prime} 00^{\prime \prime}$ & $53^{\circ} 36^{\prime} 34^{\prime \prime}$ & 4,18 & 2,65 & 3,21 \\
\hline & 05 - Cerro dos Andradas & $30^{\circ} 31^{\prime} 28^{\prime \prime}$ & $53^{\circ} 31^{\prime} 46^{\prime \prime}$ & 4,64 & 4,52 & 4,62 \\
\hline & 06 - Cerros Andradas Norte & $30^{\circ} 27^{\prime} 19^{\prime \prime}$ & $53^{\circ} 30^{\prime} 52^{\prime \prime}$ & 4,48 & 4,24 & 3,32 \\
\hline & 07 - Pedreira de talco & $30^{\circ} 26^{\prime} 13^{\prime \prime}$ & $53^{\circ} 30^{\prime} 21^{\prime \prime}$ & 2,48 & 2,24 & 4,90 \\
\hline & 08 - Dobra recumbente BR-392 & $30^{\circ} 24^{\prime} 06^{\prime \prime}$ & $53^{\circ} 30^{\prime} 02^{\prime \prime}$ & 2,76 & 2,70 & 3,13 \\
\hline \multirow{15}{*}{ 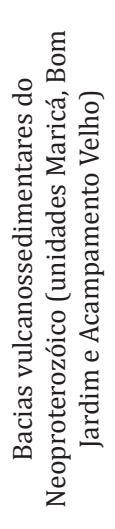 } & 09 - Passo da Promessa & $30^{\circ} 27^{\prime} 05^{\prime \prime}$ & $53^{\circ} 39^{\prime} 40^{\prime \prime}$ & 3,26 & 2,56 & 2,45 \\
\hline & 10 - Passo das Ilhas BR-290 & $30^{\circ} 21^{\prime} 36^{\prime \prime}$ & $53^{\circ} 28^{\prime} 18^{\prime \prime}$ & 3,46 & 2,56 & 2,61 \\
\hline & 11 - Pedreira de lamprófiros - Santa Fé & $30^{\circ} 45^{\prime} 11^{\prime \prime}$ & $53^{\circ} 46^{\prime} 15^{\prime \prime}$ & 2,42 & 2,36 & 4,77 \\
\hline & 12 - Cerro dos Martins & $30^{\circ} 42^{\prime} 59^{\prime \prime}$ & $53^{\circ} 29^{\prime} 01^{\prime \prime}$ & 4,88 & 4,40 & 4,48 \\
\hline & 13 - Cerro da Angélica & $30^{\circ} 37^{\prime} 03^{\prime \prime}$ & $53^{\circ} 23^{\prime} 15^{\prime \prime}$ & 5,26 & 5,76 & 4,05 \\
\hline & 14 - Cortes BR-153 arroio Lajeado & $30^{\circ} 25^{\prime} 41^{\prime \prime}$ & $53^{\circ} 22^{\prime} 10^{\prime \prime}$ & 2,24 & 2,52 & 3,03 \\
\hline & 15 - Pedreira argilitos BellaGres & $30^{\circ} 35^{\prime} 09^{\prime \prime}$ & $53^{\circ} 22^{\prime} 55^{\prime \prime}$ & 1,92 & 2,42 & 4,10 \\
\hline & 16 - Minas do Camaquã & $30^{\circ} 54^{\prime} 31^{\prime \prime}$ & $53^{\circ} 26^{\prime} 57^{\prime \prime}$ & 4,32 & 4,22 & 5,10 \\
\hline & 17 - Entroncamento BR-153/BR-392 & $30^{\circ} 34^{\prime} 58^{\prime \prime}$ & $53^{\circ} 23^{\prime} 31^{\prime \prime}$ & 1,88 & 2,48 & 3,40 \\
\hline & 18 - Cerro do Bugio & $30^{\circ} 27^{\prime} 34^{\prime \prime}$ & $53^{\circ} 35^{\prime} 58^{\prime \prime}$ & 5,76 & 5,65 & 3,55 \\
\hline & 19 - Cascata do Pessegueiro & $30^{\circ} 28^{\prime} 38^{\prime \prime}$ & $53^{\circ} 35^{\prime} 11^{\prime \prime}$ & 4,34 & 2,97 & 3,22 \\
\hline & 20 - Cerro do Espinilho & $30^{\circ} 24^{\prime} 37^{\prime \prime}$ & $53^{\circ} 34^{\prime} 13^{\prime \prime}$ & 4,88 & 5,00 & 2,98 \\
\hline & 21 - Cerro dos Machados & $30^{\circ} 26^{\prime} 34^{\prime \prime}$ & $53^{\circ} 38^{\prime} 10^{\prime \prime}$ & 4,84 & 4,96 & 3,12 \\
\hline & 22 - Cerro dos Nascimentos & $30^{\circ} 25^{\prime} 13^{\prime \prime}$ & $53^{\circ} 38^{\prime} 12^{\prime \prime}$ & 4,18 & 4,16 & 3,57 \\
\hline & 23 - Mirador Espinilho BR-290 & $30^{\circ} 22^{\prime} 19^{\prime \prime}$ & $53^{\circ} 34^{\prime} 24^{\prime \prime}$ & 3,28 & 3,85 & 2,73 \\
\hline \multirow{8}{*}{ 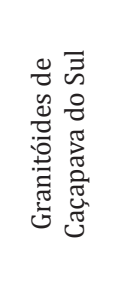 } & 24 - Matacões vila Frigorífico & $30^{\circ} 26^{\prime} 54^{\prime \prime}$ & $53^{\circ} 29^{\prime} 42^{\prime \prime}$ & 3,26 & 3,35 & 4,97 \\
\hline & 25 - Cerro do Perau & $30^{\circ} 27^{\prime} 04^{\prime \prime}$ & $53^{\circ} 28^{\prime} 25^{\prime \prime}$ & 5,84 & 6,13 & 3,95 \\
\hline & 26 - Cerro do Reginaldo & $30^{\circ} 26^{\prime} 08^{\prime \prime}$ & $53^{\circ} 26^{\prime} 17^{\prime \prime}$ & 5,66 & 5,75 & 4,13 \\
\hline & 27 - Cascata do Salso & $30^{\circ} 34^{\prime} 09^{\prime \prime}$ & $53^{\circ} 26^{\prime} 53^{\prime \prime}$ & 3,86 & 2,95 & 3,30 \\
\hline & 28 - Matacões Capela Santo Antônio & $30^{\circ} 36^{\prime} 14^{\prime \prime}$ & $53^{\circ} 25^{\prime} 32^{\prime \prime}$ & 2,84 & 3,00 & 3,87 \\
\hline & 29 - Matacões CORSAN & $30^{\circ} 31^{\prime} 11^{\prime \prime}$ & $53^{\circ} 28^{\prime} 51^{\prime \prime}$ & 2,06 & 3,04 & 4,13 \\
\hline & 30 - Chácara do Forte & $30^{\circ} 30^{\prime} 25^{\prime \prime}$ & $53^{\circ} 30^{\prime} 04^{\prime \prime}$ & 3,42 & 3,40 & 3,43 \\
\hline & 31 - Paredão BR-392 & $30^{\circ} 30^{\prime} 36^{\prime \prime}$ & $53^{\circ} 27^{\prime} 59^{\prime \prime}$ & 2,50 & 2,90 & 3,33 \\
\hline \multirow{15}{*}{ 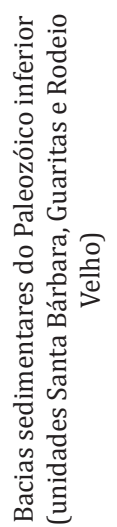 } & 32 - Cortes Santa Fé RS-357 & $30^{\circ} 44^{\prime} 54^{\prime \prime}$ & $53^{\circ} 45^{\prime} 40^{\prime \prime}$ & 2,28 & 2,48 & 3,07 \\
\hline & 33 - Granja Don Augusto RS-357 & $30^{\circ} 40^{\prime} 08^{\prime \prime}$ & $53^{\circ} 36^{\prime} 31^{\prime \prime}$ & 2,68 & 3,30 & 3,40 \\
\hline & 34 - Corte Altos da Serra RS-357 & $30^{\circ} 42^{\prime} 59^{\prime \prime}$ & $53^{\circ} 40^{\prime} 25^{\prime \prime}$ & 2,28 & 2,60 & 3,07 \\
\hline & 35 - Arroio Carajá & $30^{\circ} 46^{\prime} 38^{\prime \prime}$ & $53^{\circ} 39^{\prime} 16^{\prime \prime}$ & 3,96 & 2,64 & 3,68 \\
\hline & 36 - Corte Guaritas BR-153 tenda colonial & $30^{\circ} 40^{\prime} 03^{\prime \prime}$ & $53^{\circ} 25^{\prime} 04^{\prime \prime}$ & 2,04 & 2,53 & 2,87 \\
\hline & 37 - Pedras das Guaritas & $30^{\circ} 50^{\prime} 08^{\prime \prime}$ & $53^{\circ} 30^{\prime} 09^{\prime \prime}$ & 7,28 & 7,09 & 3,68 \\
\hline & 38 - Mirador Guaritas BR-153 & $30^{\circ} 51^{\prime} 05^{\prime \prime}$ & $53^{\circ} 36^{\prime} 32^{\prime \prime}$ & 4,48 & 4,61 & 3,40 \\
\hline & 39 - Pedra da Guarda Velha (piquete) & $30^{\circ} 41^{\prime} 47^{\prime \prime}$ & $53^{\circ} 23^{\prime} 18^{\prime \prime}$ & 5,04 & 4,77 & 3,53 \\
\hline & 40 - Gruta da Varzinha & $30^{\circ} 43^{\prime} 52^{\prime \prime}$ & $53^{\circ} 17^{\prime} 00^{\prime \prime}$ & 3,72 & 2,71 & 2,90 \\
\hline & 41 - Toca das Carretas & $30^{\circ} 36^{\prime} 39^{\prime \prime}$ & $53^{\circ} 21^{\prime} 11^{\prime \prime}$ & 4,84 & 4,55 & 3,00 \\
\hline & 42 - Mirador Serra do Segredo RS-357 & $30^{\circ} 36^{\prime} 49^{\prime \prime}$ & $53^{\circ} 32^{\prime} 01^{\prime \prime}$ & 4,50 & 4,41 & 3,67 \\
\hline & 43 - Pedra do Segredo & $30^{\circ} 32^{\prime} 06^{\prime \prime}$ & $53^{\circ} 33^{\prime} 12^{\prime \prime}$ & 6,90 & 6,68 & 4,44 \\
\hline & 44 - Pedra do Leão & $30^{\circ} 32^{\prime} 48^{\prime \prime}$ & $53^{\circ} 33^{\prime} 11^{\prime \prime}$ & 6,72 & 6,63 & 3,88 \\
\hline & 45 - Passo do Meio - arroio Lanceiros & $30^{\circ} 28^{\prime} 34^{\prime \prime}$ & $53^{\circ} 32^{\prime} 45^{\prime \prime}$ & 3,50 & 2,56 & 2,98 \\
\hline & 46 - Rincão da Tigra & $30^{\circ} 51^{\prime} 15^{\prime \prime}$ & $53^{\circ} 37^{\prime} 47^{\prime \prime}$ & 5,56 & 5,37 & 3,77 \\
\hline
\end{tabular}

Por fim, os índices de valor educativo $\left(V_{\text {educ }}\right)$ e turístico $\left(V_{\text {tur }}\right)$ destacam dois geossítios do contexto das bacias vulcanossedimentares do Neoproterozóico, notadamente: (1) o Cerro do Bugio (Fig. 3A), a oeste de Caçapava do Sul, na Serra de Santa Bárbara, com acesso complicado por estradas vicinais de "chão batido" com muitos pontilhões; e (2) o Cerro da Angélica (Fig. 3B), a elevação de maior visibilidade deste estudo, com fácil acesso pela BR-153 a sudeste da sede municipal. $0 \mathrm{Cer}$ ro do Bugio (419 m.s.n.m), além de seu destaque na paisagem, possui andesitos basálticos na base, sucessões piroclásticas ácidas (tufos, lapilli-tufos e tufos solda- dos) e, no topo, derrames riolíticos dispostos em camadas dobradas (visíveis em imagens de sensoriamento remoto), elementos vinculados à Formação Acampamento Velho (Zerfass \& Almeida, 1997). De seu ponto mais alto, visualizam-se uma série de outros atributos geológicos da região, como o Cerro dos Machados a oeste, a Serra do Segredo e o alto de Caçapava a sudeste, onde se localiza a cidade. Já o Cerro da Angélica, vinculado à evolução do Grupo Bom Jardim (Janikian et al., 2012), possui rochas diagnósticas de processos aluviais aflorantes em uma sucessão de camadas com evidente basculamento, que se salientam em meio aos 
campos da face oeste da elevação. Sua posição relativamente isolada e sua altitude de 380 m.s.n.m., em meio a terrenos substancialmente mais baixos, tem estimulado a prática de voo livre com decolagem a partir de seu topo. Tem havido intervenções nas proximidades do topo do Cerro da Angélica (área de preservação permanente, de acordo com a legislação), inclusive no sentido de facilitar o acesso, o que também eleva sua necessidade de proteção (ou, no caso, de intervenção cuidadosa, com licenciamento ambiental prévio). Por seus altos valores de diferenciação na paisagem e visibilidade, outras duas elevações recebem destaque no valor turístico $\left(V_{t u r}\right)$ : o Cerro dos Machados, com 490 m.s.n.m., e o Cerro do Espinilho, nas proximidades da BR-290, com excelente visibilidade a partir daquela rodovia.

Alguns geossítios salientam-se no estudo principalmente por seus valores de necessidade de proteção $\left(V_{\text {prot }}\right)$. Esse é o caso de locais onde afloram unidades raras ou representativas do ponto de vista geocientífico, mas que contêm também recursos minerais explorados através de empreendimentos de mineração, no passado ou no presente. A região das Caieiras, as indústrias de cal da BR-392, a apenas sete quilômetros do centro de Caçapava do Sul, é uma dessas áreas de extração mineral ativa. Ali, afloram mármores (calcários metamorfizados) calcíticos e dolomíticos, precipitados em ambiente marinho raso, com dados isotópicos de $\mathrm{Sr}$ que sugerem deposição no Paleoproterozóico (Neis et al., 2012). Outro geossítio com essas características é a localidade de Minas do Camaquã, onde minérios metálicos de $\mathrm{Cu}, \mathrm{Pb}, \mathrm{Zn}(\mathrm{Au}, \mathrm{Ag}$ ) foram explorados desde meados do século XX, com abandono do local em torno de 1996. A mina a céu aberto, e também as galerias subterrâneas possuem bom potencial educativo e turístico, ainda que possuam acessibilidade precária, demandando mais de $20 \mathrm{~km}$ de deslocamento em estrada vicinal, de "chão batido" (a "estrada velha da Mina"). Hoje em dia, no entanto, já há boas opções de hospedagem na região, como os empreendimentos Minas Hotel e Pousada Bellamina (turismocacapavadosul.com.br). Aquele geossítio possui, também, boa conectividade com outros geossítios representativos, como as Pedras das Guaritas, e áreas no município vizinho de Santana da Boa Vista (Cerro da Cruz, Pedra Pintada), estas últimas não avaliadas nesta pesquisa.

Outros geossítios relacionados ao conflito entre seu potencial geopatrimonial e a exploração mineral (com $V_{\text {prot }}$ altos) são: (1) a Pedreira de talco, com rochas metaultrabásicas de origem oceânica, na Colônia de Santa Bárbara, a NW de Caçapava do Sul; (2) o Cerro dos Andradas, já mencionado quando das observações quanto à degradação da Serra do Segredo, mas que possui elevações com as mesmas características imediatamente a norte (Cerro dos Andradas norte nas tabs. 1-3); (3) a Pedreira de argilitos BellaGres, explorada (hoje desativada) para obtenção de matéria-prima para cerâmicas especiais do tipo "porcelanato"; (4) o Cerro dos Martins, alvo de pesquisas minerais de cobre (Toniolo et al., 2004) e de plantio de espécies florestais exóticas em sua porção de topo; e (5) a pequena Pedreira de lamprófiros na RS-357, junto à localidade de Santa Fé, no limite do município com Lavras do Sul, cujas rochas vulcânicas singulares, além de exibirem estruturas colunares didáticas, serviram de matéria-prima para 0 asfalto que reveste aquele trecho da rodovia Caçapava-Lavras. Outros dois geossítios destacam-se no valor de necessidade de proteção $\left(V_{\text {prot }}\right)$ por estarem em áreas bastante povoadas: são (a) os Matacões da vila Frigorífico, com bom acesso desde o Campus da Unipampa, onde os terrenos com casas simples são ocupados por centenas de matacões arredondados de granito (Fig. 3C); e (b) o geossítio designado neste trabalho como Matacões da CORSAN, um terreno situado próximo à Avenida Santos Dumont, atrás de um reservatório ("caixa d'água") da CORSAN, na área urbana de Caçapava do Sul (Fig. 3D).

\subsection{Diretrizes para gestão territorial com foco no patri- mônio geológico}

Os recursos da geodiversidade sempre desempenharam um papel preponderante na economia e no quotidiano do município e dos habitantes de Caçapava do Sul. A exploração das jazidas de minerais metálicos na região das Minas do Camaquã, a atual produção de cal e calcário (corretivo de solo) na área das Caieiras, bem como a implantação de cursos de geologia, geofísica e tecnologia em mineração no campus local da Unipampa são apenas alguns exemplos dessa relação. A própria localização da cidade e do forte Dom Pedro II é, igualmente, função do destaque dos granitoides de Caçapava na geomorfologia e de seu consequente papel como ponto de observação e vigilância na época da colonização europeia e dos conflitos pelo estabelecimento das fronteiras meridionais do país. No momento atual, de acelerado desenvolvimento e, ao mesmo tempo, de conscientização sobre a necessidade da preservação do meio ambiente para as futuras gerações, a tendência mundial da geoconservação encontra em Caçapava do Sul um terreno fértil para florescer. Proteger, valorizar, divulgar e utilizar de forma sustentável os recursos naturais e, entre estes, os geossítios componentes do patrimônio geológico (ou geopatrimônio), são desafios para os quais os gestores regionais (em nível de município, associações ou consórcios de municípios) devem estar preparados, uma vez que possuem, à sua disposição, as ferramentas institucionais e legais adequadas a cada caso. 0 presente trabalho aponta, com base nos resultados da avaliação aplicada, algumas diretrizes, possibilidades e prioridades de ação para a geoconservação dos lugares destacados no estudo realizado, específico para o município de Caçapava do Sul, mas que pode suscitar reflexão sobre suas implicações regionais.

Em primeiro lugar, deve-se salientar o potencial do patrimônio geológico de Caçapava do Sul para a educa- 
ção em ciências da natureza, no ensino fundamental, e nas disciplinas de geografia e biologia do ensino médio. Esse potencial pode e deve ser empregado na correção das sérias distorções existentes no panorama educacional do município: (a) evasão escolar significativa; (b) atrasos na seriação; (c) baixa escolaridade entre os adultos; (d) fraco desempenho dos estudantes caçapavanos no Exame Nacional do Ensino Médio (ENEM), especialmente em ciências da natureza. Os geossítios de maior índice de valor educativo $\left(V_{\text {educ }}\right)$ apontados neste estudo são as Pedras das Guaritas, a Pedra do Segredo, a Pedra do Leão, o Rincão da Tigra, a Pedra da Guarda Velha, o Cerro do Perau, o Cerro do Reginaldo, o Cerro do Bugio e o Cerro da Angélica (Tab. 3). Alguns desses po- deriam constituir locais preferenciais para, através de oficinas ou minicursos com visitas a campo, qualificar, em um primeiro momento, os professores de ciências da natureza, geografia e biologia da rede pública de Caçapava do Sul, uma iniciativa que poderia partir das universidades e/ou de profissionais de outros órgãos públicos ou do terceiro setor, em parceria com as secretarias municipal e estadual de educação. Os professores teriam subsídios melhores e exemplos locais para demonstrar os conceitos relacionados às ciências da natureza, qualificando suas aulas e estimulando crianças e jovens a buscarem informação e a desenvolverem um novo olhar sobre seus locais já conhecidos.

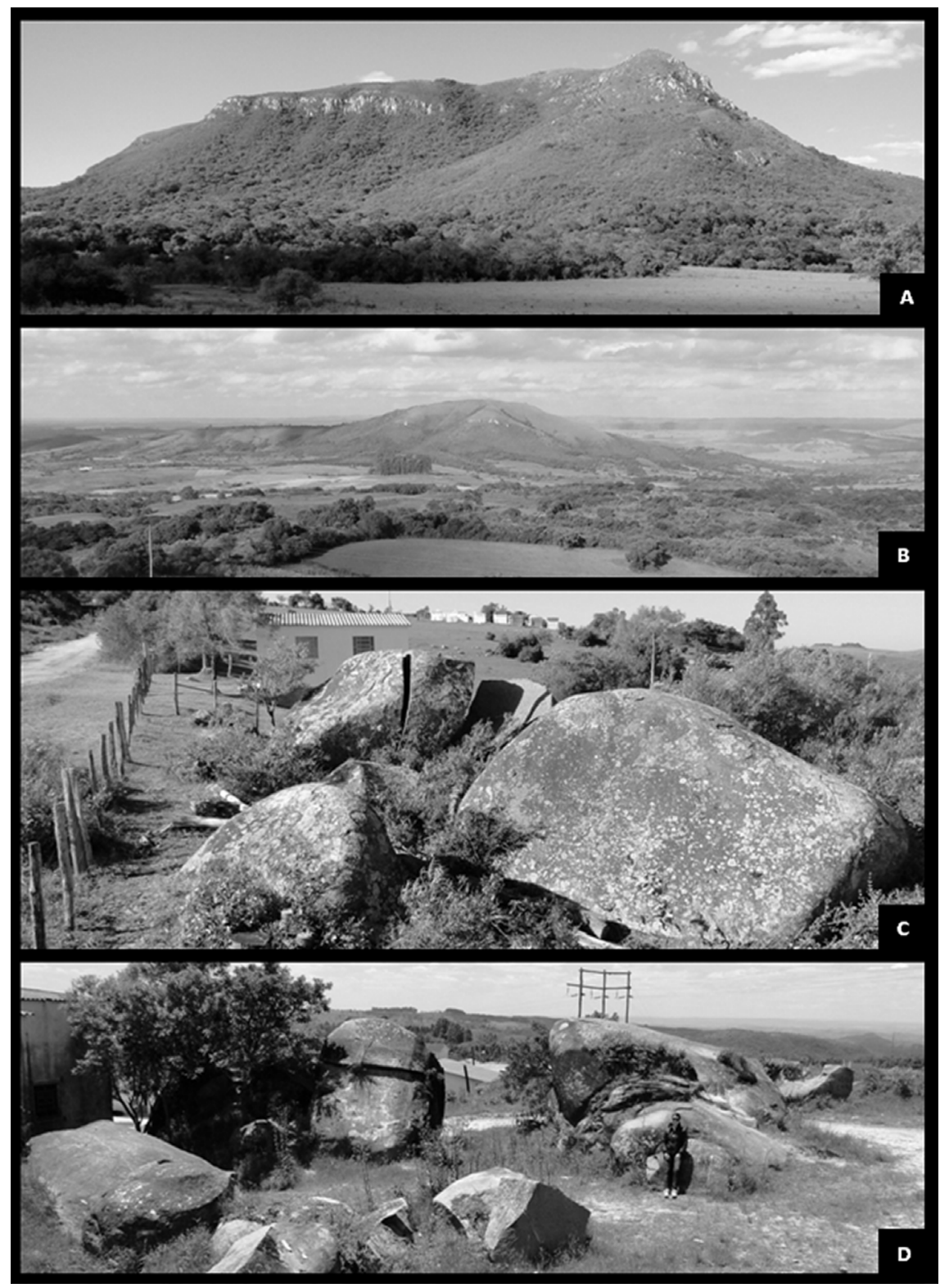

Figura 3. Alguns geossítios destacados neste trabalho: (A) o Cerro do Bugio, visto de oeste para leste, à tarde, com exposição de riolitos em sua porção de topo, importante registro de vulcanismo ácido do Neoproterozóico; (B) o Cerro da Angélica, composto por rochas sedimentares do Grupo Bom Jardim, e utilizado para decolagens de paraglider (ou parapente); (C) grandes matacões graníticos arredondados e fraturados, em exposição localizada na Vila do Frigorífico, a norte da sede municipal de Caçapava do Sul; (D) o terreno urbano dos Matacões da CORSAN, onde grandes blocos graníticos arredondados poderiam ser integrados a uma praça para a população local. 
Alguns dos geossítios da região possuem substancial potencial turístico (no caso, geoturístico), principalmente aquelas áreas já citadas no parágrafo anterior como destaques no campo da educação. Evidentemente, o assunto "geoturismo" ainda é pouco conhecido e pouco divulgado, mesmo entre profissionais e órgãos responsáveis pelo turismo no âmbito estadual e, sobretudo, municipal. No mesmo sentido, o público interessado em geoturismo, no Rio Grande do Sul e no Brasil, ainda é extremamente restrito. Ainda assim, para o futuro, uma estratégia de geoturismo para Caçapava do Sul deveria considerar o fato de que as Pedras das Guaritas e a Serra do Segredo (Pedra do Segredo/ Pedra do Leão), no mínimo, são atrativos geoturísticos singulares na América do Sul, representativos de um contexto geológico único e dotados de uma beleza paisagística impressionante. Em curto prazo, um caminho possível para o geoturismo no município é a inserção de informações geológicas corretas, mas em linguagem acessível a todos os públicos, em programas direcionados àquelas pessoas que já visitam alguns desses locais, especialmente os praticantes de esportes de aventura (Borba et al., 2011; Borba \& Souza, 2011). Os geossítios das Pedras das Guaritas, da Pedra do Segredo e da Pedra do Leão, em Caçapava do Sul, assim como outros locais nos municípios vizinhos, como o Cerro da Cruz (Santana da Boa Vista), o Rincão do Inferno (Bagé/Lavras do Sul) e a Casa de Pedra (Bagé), são muito procurados pelos praticantes de escalada em rocha, enquanto o Cerro da Angélica, conforme salientado anteriormente, já recebe interessados no voo livre (paraglider ou parapente). A definição do meio mais adequado (painéis fixos, folhetos, visitas guiadas, etc.) à difusão da informação geológica aos esportistas deve ser objeto de estudos específicos para cada geossítio e para cada perfil de público-alvo.

Estratégias de educação e turismo, no âmbito de um programa maior de geoconservação, devem ser preferencialmente acompanhadas da proteção legal das áreas de interesse em unidades de conservação da natureza (UC). Os altos valores educativo e turístico das Pedras das Guaritas, obtidos através desta metodologia de avaliação, constituem argumentos de cunho geocientífico e geopatrimonial para reforçar a necessidade, já apontada por estudos de biodiversidade e ecologia, do estabelecimento de UC na área das Guaritas (Guadagnin et al., 2000; MMA, 2007). Dentro do Sistema Nacional de Unidades de Conservação (SNUC), que prevê unidades de proteção integral ou de uso sustentável, imagina-se como ideal e possível uma grande UC de uso sustentável, como uma Área de Proteção Ambiental (APA), que englobasse todos os $30 \mathrm{~km}^{2}$ das Pedras das Guaritas, a extensa área do Rincão da Tigra e mais alguns geossítios de interesse fora de Caçapava do Sul, como os conjuntos geomorfológicos do Cerro da Cruz e da Pedra Pintada (Santana da Boa Vista), o cânion do Rincão do Inferno (Bagé/Lavras do Sul) e a Casa de Pedra (Bagé), entre outros a serem avaliados, esta- belecendo um relativo status de proteção ambiental para toda a bacia do alto rio Camaquã e para seu curso principal. Adicionalmente, conforme proposto anteriormente por Guadagnin et al. (2000), cerros dotados de uma flora de interesse especial para conservação ou, do ponto de vista geomorfológico, com formas de relevo peculiares, poderiam receber um status de proteção integral, com sua designação como Monumento Natural. Evidentemente, por sua abrangência em mais de um município, tais iniciativas de proteção deveriam envolver os órgãos ambientais do Estado (SEMA e FEPAM) e/ou do Governo Federal (ICMBio/MMA). 0 estabelecimento de reservas particulares do patrimônio natural (RPPN), unidades de conservação privadas, de iniciativa dos proprietários das terras, também pode ser estimulado na região.

Ainda com foco na proteção do patrimônio geológico, outra UC de uso sustentável (APA) poderia ser proposta para a região a oeste e norte da sede municipal de Caçapava do Sul. Seus limites devem ser estudados com maior profundidade, mas essa UC poderia conter, em seu interior, alguns dos geossítios com os maiores índices de valor em cada um dos contextos geológicos do município: (1) os geossítios da Pedra do Segredo e da Pedra do Leão, assim como toda a Serra do Segredo e, dessa forma, toda a área de nascentes do arroio dos Lanceiros; (2) os cerros alongados, posicionados a norte do Cerro dos Andradas, com características semelhantes, mas ainda não afetados por mineração ou pesquisa mineral em larga escala; (3) o Cerro do Perau, o Cerro do Reginaldo e os Matacões da vila do Frigorífico, como registros da atividade plutônica de $550 \mathrm{Ma}$ na região e dos processos geomorfológicos atuantes sobre os granitos; e (4) as elevações mais significativas da Serra de Santa Bárbara, nomeadamente os geossítios Cerro do Bugio, Cerro do Espinilho e Cerro dos Machados, representativos do vulcanismo Acampamento Velho e da maior resistência de suas rochas ao intemperismo químico. Essa abrangência de proteção legal, totalmente inserida no município de Caçapava do Sul, representaria uma celebração da geodiversidade da região e ajudaria a promover a conservação da qualidade dos recursos hídricos dos arroios dos Lanceiros e Santa Bárbara, componentes da bacia hidrográfica do Jacuí.

As áreas das Caieiras e das Minas do Camaquã, para as quais foram obtidos os maiores índices de necessidade de proteção $\left(V_{\text {prot }}\right)$ deste estudo, poderiam constituir focos para grupos de estudantes e/ou turistas, não apenas por seus aspectos geopatrimoniais. A localidade de Minas do Camaquã representa uma fase importante da extração de metais no Rio Grande do Sul, e a exploração do calcário como corretivo de solo possui um significado extraordinário para a agricultura da soja e, com ela, para toda a economia do Estado. Além disso, algumas das empresas receberam, por força de ajustamentos de conduta com o Ministério Público do RS, melhorias significativas em seus aspectos de cuidado com o meio ambiente, as quais também poderiam 
ser utilizadas como ferramentas educacionais. Entretanto, áreas de mineração, tanto ativas quanto abandonadas, apresentam peculiaridades e riscos, e seu aproveitamento em educação/turismo depende de acordos com as empresas responsáveis pela operação das pedreiras. Por esse motivo, e ainda pelo caráter efêmero e não permanente de cortes ou sítios de extração, a área das Caieiras foi avaliada como um todo, e não em seus detalhes. Uma estratégia viável para essas áreas, no sentido de estimular a divulgação de sua importância (e de suas características geológicas) a públicos distintos, seria uma parceria entre entes governamentais (ou não-governamentais) e alguma das empresas privadas, eventualmente interessada no assunto. Mediante estudos técnico-científicos específicos, esta empresa poderia até mesmo reservar (conservar) uma parte da área de extração, estabelecendo acessos seguros a grupos de visitação esporádicos. 0 mesmo conceito poderia ser utilizado para a cava a céu aberto das Minas do $\mathrm{Ca}$ maquã e, mediante adequações severas visando à segurança dos visitantes, até mesmo para alguma das suas galerias subterrâneas.

Examina-se, agora, a questão dos miradores em rodovias asfaltadas. Entre os 46 geossítios avaliados neste estudo, três eram pontos em que poderiam ser implantadas estruturas para o estacionamento de al- guns automóveis, uma barreira física simples e um painel com informações geológicas em linguagem acessível (as "mudanças aceitáveis", neste caso, necessárias). 0 potencial mirador que obteve a nota mais alta foi o Mirador Serra do Segredo, uma saibreira utilizada eventualmente (possivelmente pela municipalidade) e localizada na RS-357, na localidade de Capão das Galinhas, a menos de $10 \mathrm{~km}$ de Caçapava do Sul. Daquele ponto, tem-se um panorama espetacular da porção sudeste da Serra do Segredo, com seus cerros ruiniformes, especialmente pela manhã (Fig. 4A). Sugere-se, como diretriz de gestão territorial, que a municipalidade reserve uma fração da gleba para implantar a estrutura necessária (estacionamento e trapiche) ao seu aproveitamento educativo/turístico. Um painel com informações geológicas deve ser preparado mediante estudos específicos, inclusive com relação ao conteúdo científico e à linguagem a ser utilizada na comunicação. Intervenções no Mirador Guaritas, situado nas proximidades do rio Camaquã, no extremo sul do município, e muito mais distante da paisagem focalizada (Fig. 4B), poderiam aguardar uma avaliação da resposta e do desempenho do seu correspondente da Serra do Segredo. O ponto marcado como Mirador Espinilho, estrategicamente situado na BR-290, uma rodovia com importante trânsito de turistas argentinos na temporada de verão,

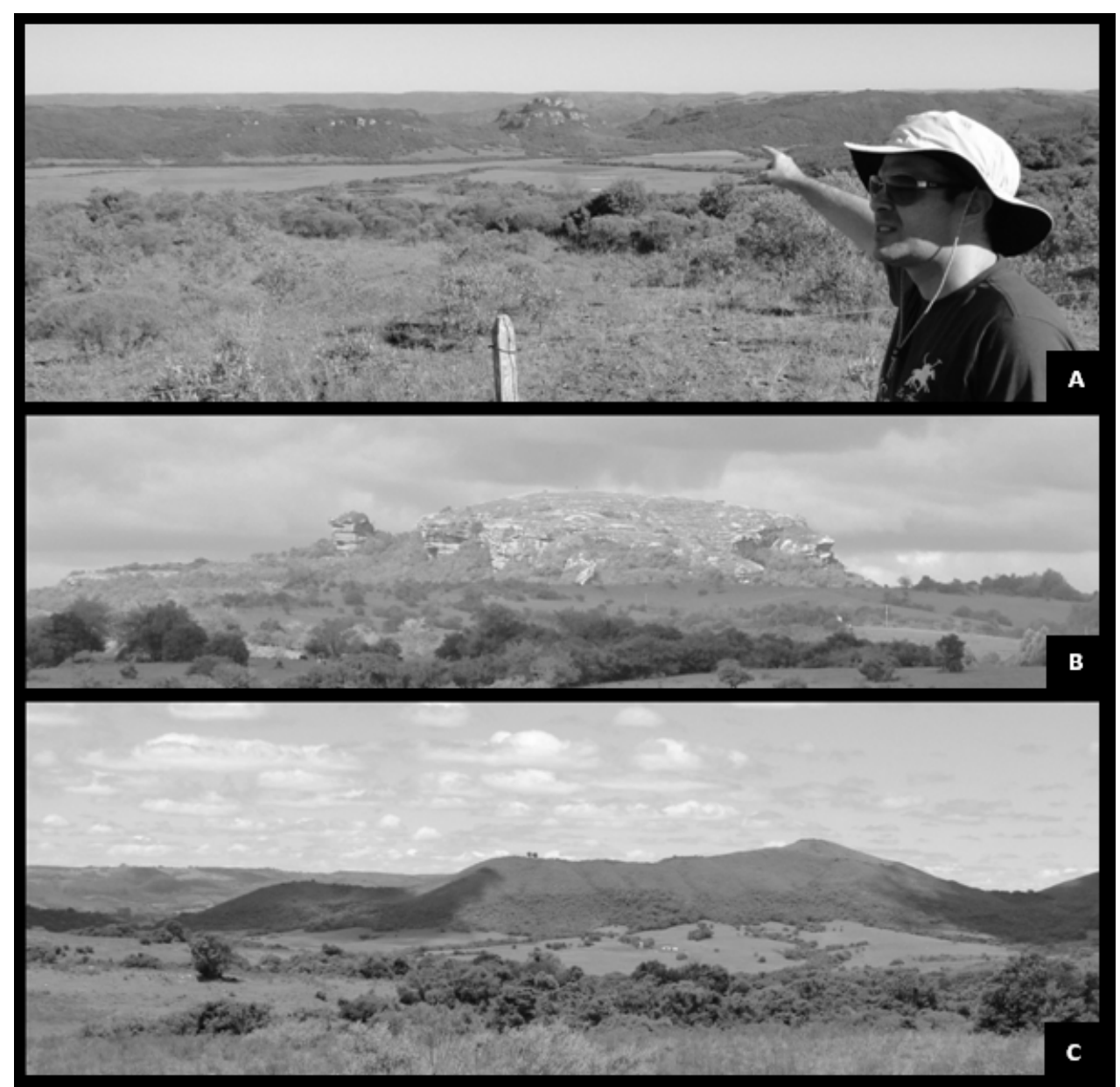

Figura 4. Potenciais miradores no Município de Caçapava do Sul: (A) o Mirador Serra do Segredo, na localidade de Capão das Galinhas, na RS-357 (a estrada Caçapava-Lavras), aquele avaliado como de implantação prioritária; (B) a paisagem das Pedras das Guaritas vista desde o potencial Mirador Guaritas, na BR-153; (C) a vista da Serra de Santa Bárbara desde o potencial Mirador Espinilho, na BR-290, que poderia constituir um elemento de atração de turistas (inclusive argentinos) que trafegam por aquela rodovia, especialmente no verão. 
deve ser analisado com atenção. Um painel naquele local poderia conter não apenas informações a respeito da paisagem visualizada (Fig. 4C), mas também sobre todos os atributos geoturísticos de Caçapava do Sul, sendo um elemento de atração de "geoturistas" em potencial, que estejam trafegando pela rodovia. Outra peculiaridade do geoturismo na região, assim como em toda a "metade sul" do Rio Grande do Sul, e que fica evidente neste potencial mirador, é a de que as informações geocientíficas devem ser divulgadas sempre em português e em espanhol.

Outra observação importante sobre os miradores refere-se ao estabelecimento de uma zona de restrição (um buffer) à implantação de talhões de plantio de espécies exóticas de crescimento rápido, como pinheiros e eucaliptos, mesmo que a área não esteja contemplada no interior de UC. Essa é uma medida importante para evitar a degradação da paisagem a ser observada, e ainda mais premente devido ao fato de que os empreendimentos de silvicultura são desenvolvidos junto às estradas e rodovias, para facilitar o escoamento da produção vegetal. A figura 5A-C demonstra, com um exemplo do extremo oeste de Caçapava do Sul (coordenadas geográficas $30^{\circ} 22^{\prime} 27^{\prime \prime} / 53^{\circ} 35^{\prime} 46^{\prime \prime}$ - BR-290, limite com
São Sepé), como um potencial mirador pode ser degradado em seus atributos de visualização da paisagem. 0 cenário original (Fig. 5A) traz um perfil geomorfológico característico do contexto das bacias vulcanossedimentares do Neoproterozoico (unidades Maricá, Bom Jardim e Acampamento Velho), onde os riolitos se salientam na paisagem por sua maior resistência ao intemperismo, dando origem ao Cerro dos Machados (a leste, esquerda) e ao Cerro dos Nascimentos (a oeste, direita). As fotografias subsequentes (Figs. 5B-C) mostram como a paisagem foi progressivamente obliterada pelo crescimento rápido das árvores exóticas, a partir da implantação dos talhões de silvicultura, inviabilizando assim um potencial mirador. Justifica-se, a partir desse exemplo, a necessidade do buffer, restringindo esse tipo de uso do solo entre o mirador efetivamente implantado e a paisagem que se objetiva divulgar.

Finalmente, é importante destacar um geossítio situado dentro da área urbana de Caçapava do Sul: o terreno dos Matacões da CORSAN (Fig. 3D). Hoje, o referido terreno, com matacões de granito de grandes dimensões, está desocupado, mal cuidado, e serve como depósito eventual de resíduos e foco de outros problemas sociais. Por sua proximidade com a Avenida Santos

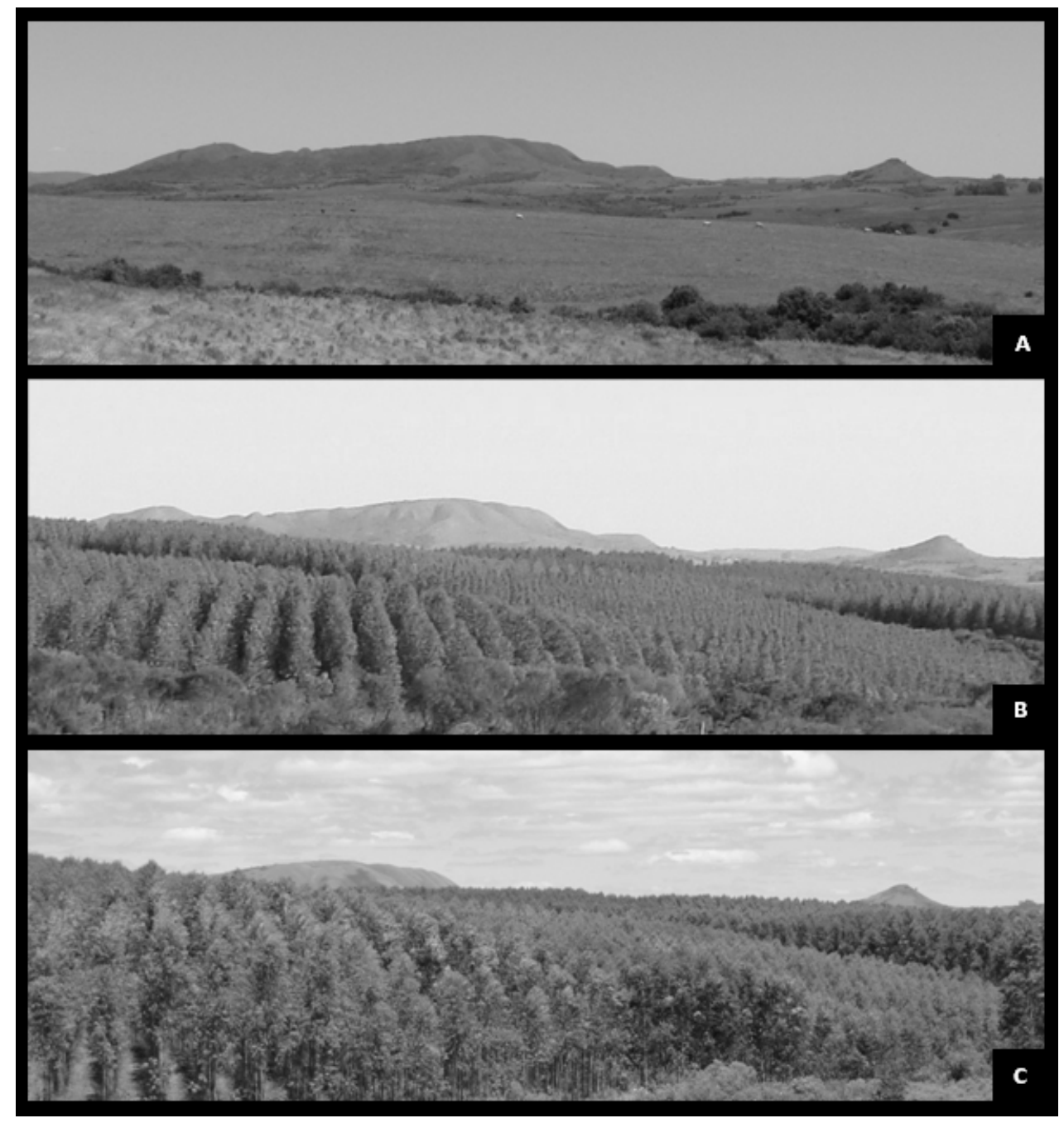

Figura 5. A progressiva ocultação de uma paisagem (e degradação de um potencial mirador) pela implantação de empreendimento de silvicultura (no caso, eucaliptos) em um ponto da BR-290 no limite de Caçapava do Sul e São Sepé: fotografias da paisagem original (A) e da mesma paisagem, a partir do crescimento rápido das árvores exóticas em maio de 2009 (B) e fevereiro de 2011 (C). 
Dumont, utilizada nos finais de tarde para caminhadas dos moradores locais, o local poderia ser transformado em uma praça, com canteiros bem cuidados, alguns equipamentos simples de alongamento e um painel informativo sobre a formação dos granitoides de Caçapava do Sul e seu estilo de afloramento em forma de matacões arredondados. Ainda que fuja ao escopo deste artigo, não se pode deixar de mencionar que estratégias de geoturismo devem ser integradas a providências para qualificar a região também em seus aspectos histórico-culturais. Por isso, deve-se investir também em tais atributos, como o Forte Dom Pedro II (praticamente abandonado) e as casas históricas do centro da cidade (casas de Borges de Medeiros e Ulhôa Cintra, entre outras, em mau estado de conservação). Por fim, sugere-se que entidades públicas, privadas e do terceiro setor, incluindo necessariamente as universidades envolvidas na pesquisa e no ensino superior na região (Universidade Federal do Rio Grande do Sul, Universidade Federal de Santa Maria, Universidade Federal do Pampa, Universidade do Vale do Rio dos Sinos, entre outras), estabeleçam uma rede de cooperação para implementar as medidas necessárias para uma gestão sustentável do patrimônio geológico de Caçapava do Sul em uma estrutura do tipo "geoparque" (McKeever \& Zouros, 2005).

\section{Considerações finais}

O inventário do patrimônio geológico do município de Caçapava do Sul, aqui apresentado, contemplou 46 geossítios representativos de todos os principais contextos geológicos do território analisado. A lista de geossítios constantes deste trabalho pode (e deve) ser ampliada e aperfeiçoada, de acordo com a experiência de diferentes grupos de pesquisa e com o desenvolvimento educacional da região, especialmente considerando a existência de um curso de graduação em geologia (Unipampa) na cidade de Caçapava do Sul e o interesse geocientífico permanente que a região desperta. A avaliação quantitativa aqui divulgada, mediante a aplicação da metodologia introduzida por Fassoulas et al. (2012), com algumas modificações, revelou-se adequada à definição daqueles elementos geológicos mais relevantes em termos de valor educativo (Veduc), valor turístico (Vtur) e valor de necessidade de proteção (Vprot). Tais índices, tomados comparativamente dentro da lista de geossítios analisados, permitem o necessário estabelecimento de prioridades para gestão territorial com foco no patrimônio geológico. No caso desta avaliação, em Caçapava do Sul, foi possível apontar os locais adequados para implantar projetos educacionais, para estabelecer roteiros geoturísticos, para criar unidades de conservação da natureza (UC) e para instalar miradores de observação da paisagem. 0 desenvolvimento de metodologias de valoração específicas e distintas para miradores, afloramentos pontuais de interesse apenas didático, e grandes áreas de potencial múltiplo poderá auxiliar, no futuro, a solucionar eventuais distorções. Na mesma linha, sugerem-se pesquisas no sentido de tornar alguns dos critérios menos subjetivos, se possível com auxílio de ferramentas de geoprocessamento e sistemas de informações geográficas (SIG). Espera-se que este trabalho seja apenas o marco inicial de um processo interdisciplinar e interinstitucional de pesquisa, proteção, valorização e divulgação do patrimônio geológico do município de Caçapava do Sul, como elemento essencial na socialização do conhecimento e no caminho para o desenvolvimento sustentável das populações locais.

Agradecimentos - 0 presente trabalho é resultado do projeto de pesquisa "Geodiversidade e patrimônio geológico da região de Caçapava do Sul (Rio Grande do Sul, Brasil): potencial para a geoconservação, o geoturismo, a educação ambiental e o desenvolvimento sustentável", coordenado pelo primeiro autor (bolsista CNPq - processo 307579/20093) e executado na Unidade de Assessoramento Ambiental do Ministério Público do Estado do Rio Grande do Sul (UAA/ DAT/MPRS). Os autores agradecem o apoio de Marcelo Lusa e Patrícia de Freitas Ferreira, ambos servidores da Unipampa/ Caçapava do Sul. Cristina Guimarães de Borba, Cassiano Pamplona Lisboa e Lais Moraes foram companheiros incansáveis nas visitas a campo e nas "geoaventuras" pela Serra das Encantadas. 0 primeiro autor agradece, ainda, à cidade de São Borja, na Fronteira Oeste gaúcha, local onde a maior parte deste trabalho foi escrita, e a seu povo simples, cordial e acolhedor.

\section{Referências}

Almeida, D.P.M., Conceição, R.V., Chemale Jr., F., Koester, E., Borba, A.W. \& Petry, K. 2005. Evolution of heterogeneous mantle in the Acampamento Velho and Rodeio Velho volcanic events, Camaquã Basin, Southern Brazil. Gondwana Research, 8(4): 479-492.

Almeida, D.P.M., Chemale Jr., F. \& Machado, A. 2012. Late to Post-Orogenic Brasiliano-Pan-African Volcano-Sedimentary Basins in the Dom Feliciano Belt, Southernmost Brazil. In: Petrology - New Perspectives and Applications, Edited by Ali Ismail Al-Juboury. p 73-130.

Bitencourt, M.F.A.S. 1983. Metamorfitos da região de Caçapava do Sul, RS: geologia e relações com o corpo granítico. In: SIMPÓSIO SUL-BRASILEIRO DE GEOLOGIA,1, Porto Alegre, Atas..., Porto Alegre, RS, pp. 37-49.

Borba, A.W. 2006. Evolução geológica da "Bacia do Camaquã" (Neoproterozóico e Paleozóico inferior do Escudo Sul-rio-grandense, RS, Brasil): uma visão com base na integração de ferramentas de estratigrafia, petrografia e geologia isotópica. Porto Alegre, 110p, Tese de Doutorado, Programa de Pós-graduação em Geociências, Instituto de Geociências, Universidade Federal do Rio Grande do Sul.

Borba, A.W. 2011. Geodiversidade e geopatrimônio como bases para estratégias de geoconservação: conceitos, abordagens, métodos de avaliação e aplicabilidade no contexto do Estado do Rio Grande do Sul. Pesquisas em Geociências, 38 (1): 3-13.

Borba, A.W. \& Mizusaki, A.M.P. 2003. Santa Bárbara Formation (Caçapava do Sul, Southern Brazil): depositional sequences and evolution of an Early Paleozoic post-col- 
lisional basin. Journal of South American Earth Sciences, 16: 365-380.

Borba, A.W. \& Souza, L.F. 2010. The Pampa of southernmost Brazil: a region requiring geoconservation and geopark strategies. In: European Geoparks Conference, 9, Lesvos, Greece, Abstracts..., Lesvos, p. 147.

Borba, A.W., Vignol-Lelarge, M.L.M. \& Mizusaki, A.M.P. 2002. Uplift and denudation of the Caçapava do Sul granitoids (Southern Brazil) during Late Paleozoic and Mesozoic: constraints from apatite fission-track data. Journal of South American Earth Sciences, 15: 683-692.

Borba, A.W., Lima, E.F., Vignol-Lelarge, M.L.M., Mizusaki, A.M.P., Sparrenberg, I. \& Barros, C.E. 2003. Significance of Late Paleozoic fission-track ages in volcanic rocks from the Lavras do Sul region, southernmost Brazil. Gondwana Research, 6(1): 79-88.

Borba, A.W., Maraschin, A.J., Noronha, F.L., Casagrande, J. \& Mizusaki, A.M.P. 2007. Provenance of the Bom Jardim Group (Neoproterozoic, Southern Brazil): evidence from petrography, geochemistry and Neodymium isotopes. Latin American Journal of Sedimentology and Basin Analysis, 14(1): 65-87.

Borba, A.W., Mizusaki, A.M.P., Santos, J.O.S., McNaughton, N.J. \& Hartmann, L.A. 2008. U-Pb zircon and ${ }^{40} \mathrm{Ar}-{ }^{39} \mathrm{Ar}$ K-feldspar dating of syn-sedimentary volcanism of the Neoproterozoic Maricá Formation: constraining the age of foreland basin inception and inversion in the Camaquã Basin of southern Brazil. Basin Research, 20: 359-375.

Borba, A.W., Souza, L.F., Porto, P.R. \& Petry, A.C. 2011. A paisagem da Serra do Segredo (Caçapava do Sul, RS) como patrimônio geológico brasileiro: características, riscos à integridade e estratégias de conservação. In: SIMPÓSIO BRASILEIRO DE PATRIMÔNIO GEOLÓGICO, 1, Rio de Janeiro, Atas..., p. 9.

Brilha, J.B.R. 2005. Património geológico e geoconservação. Palimage Editores, Viseu, 190p.

Bruschi, V.M. 2007. Desarrollo de uma metodología para la caracterización, evaluación y gestión de los recursos de la geodiversidad. Santander. 264p. Tésis Doctoral, Universidad de Cantabria, España.

Camara, G., Souza, R.C.M., Freitas, U.M. \& Garrido, J. 1996. SPRING: Integrating remote sensing and GIS by object-oriented data modeling. Computers \& Graphics, 20 (3): 395-403.

Carvalho, P.F. 1932. Reconhecimento geológico no Estado do Rio Grande do Sul. Boletim 66 do Instituto Geológico e Mineralógico do Brasil, pp. 1-72.

Chaves, C.D.R., Remus, M.V.D. \& Rizzardo, R. 2011. Assembleias minerais de baixo grau indicativas de metamorfismo de fundo oceânico nos metabasitos do arroio $\mathrm{Mu}$ dador, Caçapava do Sul/RS. In: SALÃO DE INICIAÇÃO CIENTÍFICA, 23, UFRGS, Resumos..., disponível on-line em http://www.lume.ufrgs.br/handle/10183/47052.

Chemale Jr., F. 2000. Evolução geológica do Escudo Sul-rio-grandense. In: Holz, M. \& De Ros, L.F. (Eds.) Geologia do Rio Grande do Sul, Edições CIGO/UFRGS, pp. 13-52.

Costa, A,F.U., Shukowsky, W., Fernandes, L.A.D., Nardi, L.V.S. \& Bitencourt, M.F.A.S. 1995. Modelamento gravimétrico 3D do Complexo Granítico de Caçapava do Sul, RS. In: CONGRESSO INTERNACIONAL DA SOCIEDADE BRASILEIRA DE GEOFÍSICA,3, Resumos Expandidos..., Rio de Janeiro, RJ, pp. 753-758.

CPRM - Companhia de Pesquisa de Recursos Minerais. 1995. Passo do Salsinho - Folha SH.22-Y-A-I-4. Programa Levan- tamentos Geológicos Básicos do Brasil, MME-SMM-CPRM, 339p. + apêndices.

CPRM - Companhia de Pesquisa de Recursos Minerais. 2009. Mapa geodiversidade do Rio Grande do Sul. SGMTM, CPRM, Brasília.

Fassoulas, C., Mouriki, D., Dimitriou-Nikolakis, P. \& Iliopoulos, G. 2012. Quantitative assessment of geotopes as an effective tool for geoheritage management. Geoheritage, 4(3): 177-193.

Fuertes-Gutiérrez, I. \& Fernández-Martínez, E. 2010. Geosites inventory in the Leon Province (Northwestern Spain): a tool to introduce geoheritage into regional environmental management. Geoheritage, 2: 57-75.

Gray, M. 2004. Geodiversity: valuing and conserving abiotic nature. Wiley, Chichester, 448p.

Gray, M. 2008. Geodiversity: developing the paradigm. Proceedings of the Geologists' Association, 119: 287-298.

Guadagnin, D.L., Larocca, J. \& Sobral, M. 2000. Flora vascular de interesse para a conservação na bacia do arroio João Dias: avaliação ecológica rápida. In: Ronchi, L.H. (Org.). As Minas do Camaquã: um estudo multidisciplinar - Meio Ambiente, História, Geologia, Pedologia, Biologia, Arquitetura, Direito. São Leopoldo: Editora da Unisinos, pp. 71-84.

Hartmann, L.A., Porcher, C.C. \& Remus, M.V.D. 2000. Evolução das rochas metamórficas do Rio Grande do Sul. In: Holz, M. \& De Ros, L.F. (Eds.) Geologia do Rio Grande do Sul, Edições CIGO/UFRGS, pp. 79-118.

Hartmann, L.A., Santos, J.O.S. \& McNaughton, N.J. 2008. Detrital zircon $\mathrm{U}-\mathrm{Pb}$ age data, and Precambrian provenance of the Paleozoic Guaritas Formation, Southern Brazilian Shield. International Geology Review, 50: 364-374.

Henriques, M.H., Pena dos Reis, R., Brilha, J.B.R. \& Mota, T. 2011. Geoconservation as an emerging geoscience. Geoheritage, DOI 10.1007/s12371-011-0039-8, publicado on-line em 21/4/2011.

Janikian, L., Paes de Almeida, R., Fragoso-Cesar, A.R.S., Martins, V.T.S., Dantas, E.L., Tohver, E., McReath, I. \& D’Agrella-Filho, M.S. 2012. Ages (U-Pb SHRIMP and LA ICPMS) and stratigraphic evolution of the Neoproterozoic volcano-sedimentary successions from the extensional Camaquã Basin, Southern Brazil. Gondwana Research, 21 (23): 466-482.

Justus, J.O., Machado, M.L.A. \& Franco, M.S.M. 1986. Geomorfologia. In: Levantamento de Recursos Naturais, v. 33, Folha SH.22 Porto Alegre e parte das folhas SH.21 e SI.22. Rio de Janeiro, SEPLAN - IBGE, pp. 313-404.

Leite, J.A.D., McNaughton, N.J., Hartmann, L.A., Chemale Jr., F. \& Remus, M.V.D. 1995. SHRIMP U/Pb zircon dating applied to the determination of tectonic events: the example of the Caçapava do Sul Batholith, Pedreira Inducal, Caçapava do Sul, Brazil. In: SIMPÓSIO NACIONAL DE ESTUDOS TECTÔNICOS, 5, Anais..., Gramado, RS, pp. 389390.

Leinz, V., Barbosa, A.F. \& Teixeira, E. 1941. Mapa geológico Caçapava-Lavras. Boletim 90, Secretaria da Agricultura, Indústria e Comércio - RS, 39p.

Lima, F.F., Brilha, J.B.R. \& Salamuni, E. 2010. Inventorying geological heritage in large territories: a methodological proposal applied to Brazil. Geoheritage, 2: 91-99.

Maraschin, A.J., Mizusaki, A.M.P., Zwingmann, H., Borba, A.W. \& Sbrissa, G.F. 2010. Illite authigenesis in sandstones of the Guaritas Allogroup (Early Paleozoic): implications for depositional age, stratigraphy and evolution of the Camaquã Basin (Southern Brazil). Journal of South American 
Earth Sciences, 29: 400-411.

McKeever, P.J. \& Zouros, N. 2005. Geoparks: celebrating Earth heritage, sustaining local communities. Episodes, 28(4): 274-278.

MMA - Ministério do Meio Ambiente. 2007. Áreas prioritárias para conservação, uso sustentável e repartição de benefícios da biodiversidade brasileira: atualização. Portaria MMA 9, 23 de Janeiro de 2007. CID, MMA, Brasília.

Neis, L., Mizusaki, A.M.P., Koester, E. \& Borba, A.W. 2012. Geoquímica dos metacarbonatos do Escudo Sul-rio-grandense nas regiões de Caçapava do Sul e Arroio Grande, RS. In: CONGRESSO BRASILEIRO DE GEOLOGIA, 46, Santos, Anais..., Santos, SP.

Paim, P.S.G., Chemale Jr., F. \& Lopes, R.C. 2000. A Bacia do Camaquã. In: Holz, M. \& De Ros, L.F. (Eds.) Geologia do Rio Grande do Sul, Edições CIGO/UFRGS, pp. 231-274.

Paim, P.S.G., Fallgater, C. \& Silveira, A.S. 2010. Guaritas do Camaquã, RS: exuberante cenário com formações geológicas de grande interesse didático e turístico. In: Winge, M., Schobbenhaus, C., Souza, C.B.G., Fernandes, A.C.S., Berbert-Born, M., Sallun-Filho, W. \& Queiroz, E.T. (Eds.) Sítios geológicos e paleontológicos do Brasil (publicado na internet em 30/8/2010 no sítio www.unb.br/ig/sigep/ sitio076/sitio076.pdf).

Pena dos Reis, R. \& Henriques, M.H. 2009. Approaching an integrated qualification and evaluation systema for geological heritage. Geoheritage, 1: 1-10.

Petry, K. \& Almeida, D.P.M. 2005. Posicionamento do magmatismo Rodeio Velho na região do Arroio Carajá, Caçapava do Sul, RS. In: SIMPÓSIO DE VULCANISMO E AMBIENTES ASSOCIADOS, 3, Cabo Frio, Resumos...Cabo Frio,RJ.

Remus, M.V.D., McNaughton, N.J., Hartmann, L.A. \& Groves, D.I. 1996. SHRIMP U/Pb dating at $2448 \mathrm{Ma}$ of the oldest igneous rock in southern Brazil: identification of the westernmost border of the Dom Feliciano Belt. In: SBG Symposium - Archean Terranes of the South American Platform, Brasília, Proceedings..., pp. 67-69.

Manuscrito 512.

Editores: Tânia M. Strohaecker \& Paulo A. Souza.
Sartori, P.L.P. \& Kawashita, K. 1985. Petrologia e geocronologia do Batólito Granítico de Caçapava do Sul, RS. In: SIMPÓSIO SUL-BRASILEIRO DE GEOLOGIA, 2, Anais..., pp. 102-107.

Sharples, C. 2002. Concepts and principles of geoconservation. Tasmanian Parks and Wildlife Service, electronic publication, 81p.

Silva, D.R.A., Mizusaki, A.M.P., Anjos, S.M.C., Koester, E. \& Borba, A.W. 2006. Provenance of fine-grained sedimentary rocks derived from $\mathrm{Rb}-\mathrm{Sr}$ and $\mathrm{Sm}-\mathrm{Nd}$ analyses: the example of the Santa Maria Formation (Triassic, Paraná Basin, Southern Brazil). Latin American Journal of Sedimentology and Basin Analysis, 13(2): 135-149.

Suertegaray, D.M.A. \& Silva, L.A.P. 2009. Tchê Pampa: histórias da natureza gaúcha. In: Pillar, V.P., Müller, S.C., Castilhos, Z.M.S. \& Jacques, A.V.A. (Eds.) Campos Sulinos: conservação e uso sustentável da biodiversidade. MMA, Brasília, DF, Cap. 3, pp. 42-59.

Toniolo, J.A., Remus, M.V.D., Macambira, M.J.B. \& Moura, C.A.V. 2004. Metalogênese do Depósito de Cobre Cerro dos Martins, RS: Revisão e Geoquímica Isotópica de Sr, S, O e C. Pesquisas em Geociências, 31: 41-67.

UFRGS. Universidade Federal do Rio Grande do Sul. 1998. Mapeamento geológico 1:25.000 de parte das folhas Durasnal, Passo do Salsinho, Caçapava do Sul e Arroio Santa Bárbara. Trabalho de Graduação, Universidade Federal do Rio Grande do Sul, inédito.

Weber, E. Hasenack, H. \& Ferreira, C.J.S. 2004. Adaptação do modelo digital de elevação do SRTM para o sistema de referência oficial brasileiro e recorte por unidade da federação. Porto Alegre, UFRGS Centro de Ecologia. ISBN 97885-63843-02-9. Disponível em http://www.ecologia. ufrgs.br/labgeo.

Zerfass, H. \& Almeida, D.P.M. 1997. Mapa geológico da região dos Cerros Bugio e Perau, Município de Caçapava do Sul, RS. Acta Geologica Leopoldensia, Série Mapas, 3: 1-15. 
